OPEN ACCESS

Edited by:

Toyonobu Fujii,

Tohoku University, Japan

Reviewed by:

Darren James Coker,

King Abdullah University of Science

and Technology, Saudi Arabia

Nafsika Papageorgiou,

University of Crete, Greece

Thanos Dailianis,

Hellenic Centre for Marine Research (HCMR), Greece

*Correspondence:

Paul G. Thomson

paul.thomson@uwa.edu.au

Specialty section:

This article was submitted to Marine Ecosystem Ecology,

a section of the journal

Frontiers in Marine Science

Received: 31 August 2018 Accepted: 23 November 2018 Published: 14 December 2018

Citation:

Thomson PG, Fowler AM, Davis AR, Pattiaratchi $C B$ and Booth DJ (2018) Some Old Movies

Become Classics - A Case Study

Determining the Scientific Value of ROV Inspection Footage on a Platform on Australia's North West

Shelf. Front. Mar. Sci. 5:471. doi: 10.3389/fmars.2018.00471

\section{Some Old Movies Become Classics A Case Study Determining the Scientific Value of ROV Inspection Footage on a Platform on Australia's North West Shelf}

\author{
Paul G. Thomson ${ }^{1 *}$, Ashley M. Fowler, ${ }^{2,3}$, Andrew R. Davis ${ }^{4}$, Charitha B. Pattiaratchi' and \\ David J. Booth ${ }^{2}$ \\ ' Oceans Graduate School and The UWA Oceans Institute, The University of Western Australia, Perth, WA, Australia, \\ ${ }^{2}$ Ecosystem Security Team, School of Life Sciences, University of Technology Sydney, Ultimo, NSW, Australia, ${ }^{3}$ School \\ of Life and Environmental Sciences, Deakin University, Burwood, VIC, Australia, ${ }^{4}$ Centre for Sustainable Ecosystem \\ Solutions and School of Biological Sciences, Faculty of Science, Medicine and Health, University of Wollongong, \\ Wollongong, NSW, Australia
}

The global oil and gas industry holds a vast archive of Remotely Operated Vehicle (ROV) inspection footage potentially containing useful long-term data on marine biological communities. With the upcoming era of decommissioning of oil and gas structures, it is timely to assess the usefulness of this footage for researching these communities. We used ROV inspection footage to characterize the sessile invertebrates and fishes associated with the Goodwyn Alpha Production Platform (GWA) on the North West Shelf of Australia between depths of 10 and $125 \mathrm{~m}$ during 2006 and 2008. Depth was a major driver of invertebrate assemblages, most likely due to specific requirements such as light, and differences between years were most likely from the physical detachment of species by cyclones and internal waves. Phototrophic species were mostly limited to the upper $50 \mathrm{~m}$ of the platform, including the hard coral Pocillopora sp. and the soft corals Nephthea sp. and Scleronephthya sp. In contrast, heterotrophic species including sponges, anemones, bryozoans, hydroids, bivalves such as Lopha folium and the hard coral Tubastrea spp., were distributed across all depths. We observed 1791 fish from at least 10 families and 19 species, including commercial species such as crimson seaperch (Lutjanus erythropterus), red emperor (L. sebae), saddle-tailed seaperch (L. malabaricus), mangrove jack (L. argentimaculatus) and trevally (Caranx spp.). Fish density increased significantly with depth during 2008, from a mean of 23 fish/50 $\mathrm{m}^{2}$ between 10 and $25 \mathrm{~m}$ to 3373 fish/50 $\mathrm{m}^{2}$ at $125 \mathrm{~m}$, where small unidentified baitfish were abundant. The highest densities of commercial species occurred between 25 and $75 \mathrm{~m}$ depth, suggesting that mid-depth platform sections had high habitat value, a consideration when selecting decommissioning options. The greatest difficulties using the video were the poor lighting and resolution that inhibited our ability to identify sessile species with high taxonomic precision. However, the footage was useful for evaluating high-level biodiversity of the platform, understanding how fish and 
invertebrate communities changed with depth and comprehending the dynamic nature of the invertebrate community over time. Understanding the habitat value of structures will be necessary for making environmentally sound decommissioning decisions in the future.

Keywords: ROV video, sessile invertebrates, commercial fish species, fish, oil platform, rigs to reef, decommissioning

\section{INTRODUCTION}

Subsea infrastructure of the oil and gas industry (hereafter 'oil structures') has proliferated in continental boundaries worldwide, with reportedly more than 7,500 structures around the world (Parente et al., 2006). Over the next two decades, most oil structures will reach end of life and require decommissioning. Decommissioning has historically involved complete removal, due to the assumption that removal represents best environmental practice. However, evidence from some oil and gas-producing nations indicates structures can act as artificial reefs, providing habitat for endangered cold-water corals (Bell and Smith, 1999; Gass and Roberts, 2006) and by developing dense encrusting invertebrate communities (Forteath et al., 1982; Friedlander et al., 2014; Kolian et al., 2017) that provide habitat for other marine organisms, including commercially valuable fish species (Rooker et al., 1997; Stanley and Wilson, 1997; Love et al., 2000). These discoveries suggest that under at least some circumstances, removal of oil and gas infrastructure will result in the loss of valuable habitat for ecologically and commercially important species. In Australia, and most parts of the world, these offshore platforms are not fished and are surrounded by a $500 \mathrm{~m}$ exclusion zone making them quasi-marine protected areas or no-take zones. Given some of these platforms have been in place for decades, they have the potential to play a significant role in the population dynamics of key species at a local or even regional scale.

The potential for oil structures to provide important habitat has led to the development of 'rigs-to-reefs' (RTR) programs in some regions. RTR programs operate on a 'win-win' premise, whereby obsolete structures are recycled as artificial reefs, while also providing substantial cost savings to industry (Macreadie et al., 2011). RTR programs have become increasingly popular since their inception in Louisiana in 1986, and have spread to numerous other US states, as well as Southeast Asian nations (Kaiser, 2006). The phrase 'RTR' is now frequently used to describe any decommissioning practice that does not involve complete removal of oil structures, including leaving part of a structure in situ.

Despite growing popularity, RTR programs remain controversial. They have historically been viewed as an opportunity for oil companies to avoid their removal obligations, particularly by environmental NGOs and the general public (Jørgensen, 2012). This has resulted in strong opposition to RTR conversions in particular regions (e.g., the North Sea), and heated public debate concerning the instigation of any new RTR program. Before a new program can be established, considerable scientific evidence is required to determine whether oil structures will provide a net benefit to the marine environment (Schroeder and Love, 2004). For example, over a decade of research was required to demonstrate that oil platforms in Southern California provide important habitat for overfished rockfish populations before legislation allowing RTR conversions could be passed in that region (Assembly Bill 2503, 2010).

In Australia, the North West Shelf (NWS) Venture is supported by numerous platforms, well heads, production areas and support facilities connected by hundreds of kilometers of pipelines. Due to a dearth of research, very little is known about the environmental benefits of Australia's offshore oil and gas infrastructure and there is little information to inform policy development or guide upcoming decommissioning decisions. Recent studies suggest that infrastructure on the NWS is well colonized, providing habitat for sessile marine invertebrates and fishes (McLean et al., 2017, 2018b). However, understanding the habitat value of these structures with respect to decommissioning decisions will require an understanding of the variability and transiency of these communities, both with depth and through time. With particular reference to platforms, understanding the distribution of the sessile invertebrate community over depth will be important when considering decommissioning options (Claisse et al., 2015). For example, one decommissioning option for platforms is 'topping', that is, following the removal offsite of the above-water structure (or topsides), a section of the underwater supporting frame (known as the jacket) is removed down to a safe navigable depth $(\sim 30 \mathrm{~m})$ and placed on the seabed alongside the structure (Macreadie et al., 2011). Would this negatively impact on the habitat value of the structure? Has the most productive and sunlit habitat been lost to greater depths? How will this affect associated fish communities and interactions with surrounding ecosystems? Answers to these questions are critical for determining the habitat value of oil structures and the relative environmental benefit of alternative decommissioning options (Fowler et al., 2014).

An inexpensive approach to assessing the habitat value of oil and gas infrastructure is to use industry inspection footage. Oil structures are regularly inspected for operational and engineering purposes using underwater video cameras mounted on Remotely Operated Vehicles (ROVs). The oil and gas industry worldwide holds a vast archive of inspection footage dating back decades (Macreadie et al., 2018). Although collected in an imperfect scientific manner, this archive contains footage of marine fauna associating with oil and 
gas structures and surrounding habitats, making it a potential source of long-term data for biological observation (Macreadie et al., 2018; McLean et al., 2018a). The footage also covers a depth range rarely achieved by independent scientific investigations, spanning from the surface to beyond $1,000 \mathrm{~m}$ depth. Such data sources are rare in our oceans and particularly valuable, given the impacts of climate change on biological communities and the limited information available on deep sea ecosystems.

To our knowledge, we present here the first study of the biological communities associated with an offshore oil and gas platform in Australia and contribute to the few other studies carried out on NWS oil and gas infrastructure (Fowler and Booth, 2012; Pradella et al., 2014; McLean et al., 2017, 2018b). The aims of this paper are to determine: (1) the composition of the invertebrate and fish communities associated with the platform; (2) how the fish community changes with depth; and (3) how the invertebrate community changes with depth and time. While addressing these aims, we provide a preliminary evaluation of the usefulness of industry ROV footage for researching platform communities. Understanding how these communities change over depth and time will be necessary for assessing the habitat value of this and other platforms, which will be essential for making environmentally sound decommissioning decisions in the near future.

\section{MATERIALS AND METHODS}

The Goodwyn Alpha production platform (GWA), operated by Woodside Energy Ltd., is located $135 \mathrm{~km}$ north-west of Karratha, WA, Australia, on the NWS in approximately $130 \mathrm{~m}$ of water. The platform is located in a subtropical environment and in the path of the southward flowing Holloway Current that transports warm, low salinity water southwards into the Leeuwin Current. Seawater temperature in the upper $100 \mathrm{~m}$ ranges between 22 and $30^{\circ} \mathrm{C}$, peaking in April each year (Bahmanpour et al., 2016). GWA was commissioned in 1995 and has a complex subsurface structure consisting of horizontal, vertical and diagonal beams or members making up the steel frame or jacket. The jacket is periodically inspected by engineers using ROV footage for structural integrity and the extent of attached invertebrates which can result in increased hydrodynamic load on the structure.

A total pool of $8.5 \mathrm{~h}$ of digital footage of the north face or Row G of the GWA jacket was available from 2006 and 2008 (Figure 1). This face is on the leeward side of the platform and protected from the prevailing winds and swells from the south west. The footage was collected by ROV during standard industry inspections of the infrastructure. During inspections, the ROV was positioned so that the online inspection engineer had a clear view of the member being inspected, and could determine its condition. This also provided a useful view for surveying both fishes and attached sessile invertebrates. As the quality of the footage was variable and not taken for scientific purposes, the total footage pool was pre-screened to identify footage that adhered to the following criteria: (1) between 3 and $5 \mathrm{~m}$ from structure; (2) water visibility $\geq 5 \mathrm{~m}$ and; (3) ROV moving at a slow, constant speed. We estimate that $24 \%$ of the video pre-screened was unsuitable for our purposes.

\section{Sessile Invertebrate Surveys}

Sessile invertebrate communities were surveyed from multiple, replicate quadrats taken from survey footage of the horizontal members of the jacket (Figure 1). In 2006, surveys were carried out along horizontal members at depths of $15 \mathrm{~m}, 50 \mathrm{~m}, 90 \mathrm{~m}$, and $125 \mathrm{~m}$. Footage was taken between midnight and 03:00 h (Western Standard Time, WST) on August 18th, 2006. In 2008, footage was taken between $15: 00 \mathrm{~h}$ and $18: 00 \mathrm{~h}$ on the 20th December, with the exception of footage from $90 \mathrm{~m}$ depth, which was taken on the 12th December at 10:00 h. There was no suitable video footage available from the horizontal member at $125 \mathrm{~m}$ in 2008. The horizontal members were last cleaned in December 1998, therefore the 'age' of the attached community was approximately 10 years by December 2008, notwithstanding changes in composition through natural disturbances (e.g., the passage of cyclones). There was no footage available from Row $G$ between the years we surveyed.

Survey or transect lengths varied according to the length of horizontal members which increased with depth (Supplementary Table S1a). In 2006, transects ranged between $30 \mathrm{~m}$ and $65 \mathrm{~m}$. In 2008, while there was no suitable video footage available from the horizontal member at $125 \mathrm{~m}$ in 2008, at least $70 \%$ of the remaining members were surveyed for sessile invertebrates, resulting in survey lengths of between $30 \mathrm{~m}$ and $50 \mathrm{~m}$ on the upper three members.

Still frames from the transects of the horizontal members were used to set quadrats within which the sessile invertebrates were identified and their coverage quantified. To optimize the number of quadrats from the footage, frames were not random but captured sequentially every $15-30 \mathrm{~s}$ as the previous frame of the component was cleared from the field of view. Frames were captured using VLC media player (v. 2.0.5) and then imported into Coral Point Count with Excel Extensions V4.1 (CPCe) (Kohler and Gill, 2006). Within CPCe, a square quadrat border was set for each sample to the approximate diameter of horizontal member taken from engineering diagrams of the platform. This yielded quadrats of approximately $1.25 \mathrm{~m}^{2}$ at $15 \mathrm{~m}$ and $50 \mathrm{~m}$ depth, $1.5 \mathrm{~m}^{2}$ at $90 \mathrm{~m}$ and $1.75 \mathrm{~m}^{2}$ at $125 \mathrm{~m}$. At least 10 replicate quadrats were examined at each depth in each year, with the exception of $125 \mathrm{~m}$ depth (Figure 1 and Supplementary Table S1a). Prior to the video analysis, we determined the optimal number of random points per quadrat necessary to most accurately determine sessile invertebrate cover while reducing counting effort. To do so, we chose nine quadrats from GWA with low, moderate and high cover of the easily identified coral species Tubastrea sp. We then scored the presence of Tubastrea sp. in quadrats within CPCe under an increasing number of random points that increased in 5 point steps to 50 , and constructed a performance curve of score standard deviation versus random point number (Brown et al., 2004). We found that from 25 random points per quadrat, increased counting effort did not yield better estimations of Tubastrea coverage, thus chose this number as optimal for describing sessile invertebrate cover. To aid identification, the corresponding video was played 


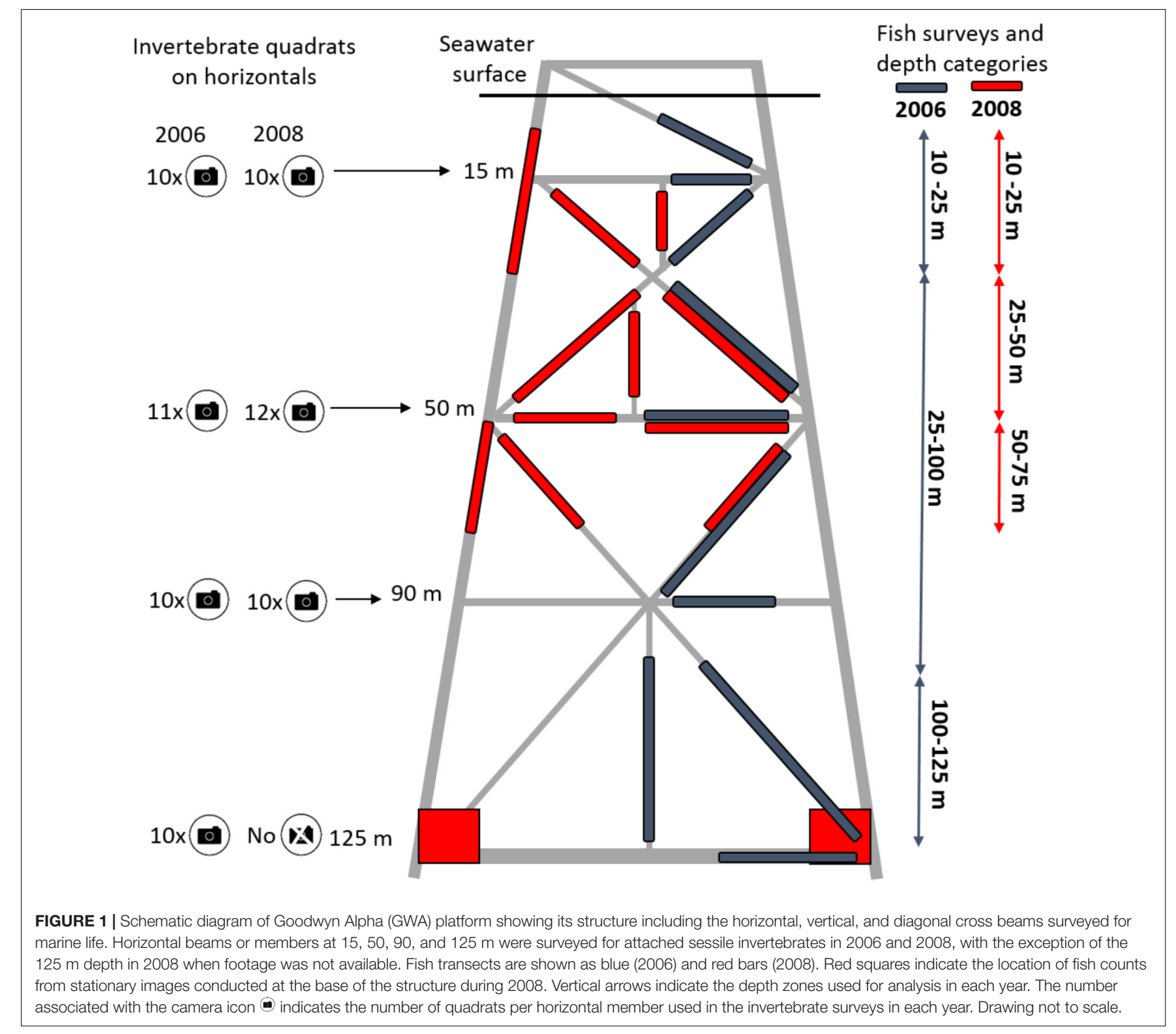

concurrently when growth on the still frames was indistinct under the points. Where possible, we used still photographs of members taken during the survey and photographs of samples returned to the surface from related engineering reports from GWA in 2008 to confirm video identifications (Woodside, 2008; Surespek Iss PTY Ltd, 2009). For classifying and identifying the invertebrates, we used the Collaborative and Automated Tools for Analysis of Marine Imagery (CATAMI) system, which introduces an Australian-wide acknowledged, standardized terminology for annotating benthic substrates and biota in marine imagery (Althaus et al., 2015).

\section{Fish Surveys}

Video used in assessing fish density included that of horizontal, vertical, and diagonal jacket members over a greater range of depths than used for the invertebrates to increase encounter rates and to account for movement (Figure 1). Fishes were surveyed from footage taken on the August 18th, 2006 and December 20th, 2008. Footage from 2006 was taken at night (midnight - 05:30 h, WST) while footage from 2008 was taken during daylight hours (15:30-18:00 h). Transect lengths varied according to member length and the available useable footage, but at least three transects were examined within each depth category (Supplementary Table S1b). In 2006, we surveyed approximately $146 \mathrm{~m}^{2}$ of platform, with transect lengths ranging between 20 and $40 \mathrm{~m}$. In 2008, suitable footage was lacking from depths $>90 \mathrm{~m}$. Therefore we used frames from stationary footage taken at the base of the legs at $125 \mathrm{~m}$ on the northeast and northwest corners of Row G (Figure 1). This footage was taken 3 months earlier on September 12th, 2008. Consequently, in 2008, we surveyed approximately $366 \mathrm{~m}^{2}$ of platform with transects of between 19 and $30 \mathrm{~m}$ length (Supplementary Table S1b). 
The depth categories differed between years due to the lack of suitable replicates required for statistical analyses in the 50-75 m category in 2006, requiring the combination of transects between the 25 and $100 \mathrm{~m}$. Some footage along the horizontals used for the invertebrate surveys were reused for surveying fish where suitable.

For each transect, fish counts began from a freeze frame generally at one end of the member. We then advanced the footage frame by frame and counted additional fish as they entered the view in front of, or to the side of the member (Caselle et al., 2002). Individuals were identified to the lowest possible taxonomic level. In 2008, fish were counted from freeze frames of the seafloor infrastructure as this footage was largely stationary. To standardize the reporting of fish densities, surface areas of the members were calculated from known dimensions of the infrastructure (GWA specifications, Woodside Energy Ltd.) and densities are reported as abundance per $50 \mathrm{~m}^{2}$.

\section{Statistical Analysis}

Percentage cover of invertebrate species was calculated for each quadrat within CPCe and each quadrat was used as an individual sample. Invertebrate communities were compared between depths and years using the statistical packages PRIMER (v6.1.14) and PERMANOVA (v1.0.40) (Clarke, 1993; Clarke and Gorley, 2006; Anderson, 2017). Percent coverage was squareroot transformed to ensure that the most abundant species did not unduly influence comparisons and a similarity matrix was constructed using the Bray-Curtis similarity coefficient. Permutational multivariate analysis of variance (PERMANOVA) was used to test the significance of differences (alpha: 0.05, 9999 permutations) between community composition at each depth within and between years. Pairwise comparisons between depths within and between years were performed using pairwise PERMANOVA tests which employ a pseudo- $t$ statistic. A Multi-Dimensional Scaling (MDS) plot was used to visualize differences in the marine growth among depths and between years. Similarity Percentage analysis (SIMPER) within PRIMER was used to identify which species/groups contributed most to community differences between depths and years. A cut-off of $80 \%$ species contribution was used in SIMPER analyses.

As our footage in alternate years was either diurnal or nocturnal, and as time of day is known to affect fish behavior, fish communities were compared among depths within each year separately. Multivariate analyses were similar to those used for the sessile invertebrates. Fish density was $\log (x+1)$ transformed and a Bray-Curtis similarity matrix was constructed. Community composition was compared among depths using the PERMANOVA routine and SIMPER analysis was used to identify species contributing up to $80 \%$ community differences between depths. Total fish density was compared among depths in 2008 using a one-way ANOVA, following inspection of the data for normality and homogeneity of variances. Tukey's post hoc tests were used to identify differences between specific depth categories.

\section{RESULTS}

\section{Sessile Invertebrates Community Composition}

We identified the invertebrate communities into broad functional and taxonomic categories, genera and species where possible (Table 1 and Figure 2). The broadest functional categories included two underlying encrusting or enveloping invertebrate and crustose algal layers. These layers were overlaid with hard and soft corals, anemones, bivalves and bryozoans and/or hydroids. Few taxa could be identified to higher taxonomic categories due to low camera resolution and lighting; however, we have included the CATAMI codes for each taxa where possible (Table 1).

The encrusting layer on the upper $50 \mathrm{~m}$ of the structure consisted primarily of a calcite layer of intact bivalves and bleached shells (Figure 2A). While the bivalves were not always clearly distinguishable in the footage, physical samples from industry reports in 2008-2009 supported these observations and confirmed that above approximately $60 \mathrm{~m}$ depth, the encrusting layer consisted primarily of living and dead bivalves, including species such as Pinctada sp. and Lopha folium of up to $190 \mathrm{~mm}$ diameter (Surespek Iss PTY Ltd., 2009). On the lower structure, from depths of $>50 \mathrm{~m}$, the enveloping layer was a colorless mat with filamentous appearance but with few other distinguishing features. Calcareous coralline algae and sponges were also distinguishable but could not be identified further.

Scleractinian stony or hard corals and octocorals (soft corals) were identified in both years (Table 1 ). Hard corals included two species of Tubastrea (Figure 2A) and one of Pocillopora sp. and photographs from industry samples confirm these observations (Surespek Iss PTY Ltd, 2009). Soft corals included two species of Scleronephthya and one of Nephthea (Figure 2B). The remaining cnidaria were the solitary true anemones, consisting of a fleshy stalk and a ring of tentacles surrounding a central mouth (Figure 2C). As we could not distinguish between bryozoans and hydroids with any confidence due to the poor resolution and lighting in the footage, we combined them into one category.

\section{Community Changes With Depth and Time}

Overall, we found a progressive change in the sessile invertebrate community with depth in both years, with the greatest changes evident between depths less than and greater than $50 \mathrm{~m}$ (Table 1 and Figures 3A,B). In 2006, coverage at $15 \mathrm{~m}$ depth was dominated by the calcite encrusting layer (42.0\%), along with $37.7 \%$ of hard coral (mostly $24.1 \%$ of Tubastrea sp. 2 and $12.7 \%$ of Pocillopora sp.) and $15.8 \%$ soft corals (mostly $12.5 \%$ of Scleronephthya sp. 1). Coverage at $50 \mathrm{~m}$ was dominated by soft corals, including Scleronephthya sp. 1 and Nephthea sp. (51.4\% and $7.8 \%$, respectively), the calcite layer $(22.5 \%)$ and the hard coral Tubastrea sp. 2 (10.5\%). At 90 and $125 \mathrm{~m}$, filamentous mat coverage was $51.8 \%$ and $65.4 \%$, respectively, hard corals were absent and soft coral cover was $42.0 \%$ at $90 \mathrm{~m}$ and $28.8 \%$ at $125 \mathrm{~m}$. Groups with minor coverage included unidentified hard and soft corals ( $0.5 \%$ and $\leq 8.5 \%$, respectively), sponges at $90 \mathrm{~m}$ depth (1.2\%) and the bryozoans/hydroids 
TABLE 1 | Invertebrate taxa and their mean percent cover on the horizontal members of Goodwyn Alpha platform in 2006 and 2008 (standard deviation shown in brackets).

\begin{tabular}{|c|c|c|c|c|c|c|c|c|}
\hline \multirow{2}{*}{$\begin{array}{l}\text { Invertebrates } \\
\text { Encrusting/enveloping }\end{array}$} & \multicolumn{4}{|c|}{ Year 2006 and depth (m) } & \multicolumn{3}{|c|}{ Year 2008 and depth (m) } & \multirow[t]{2}{*}{ CAAB\# } \\
\hline & 15 & 50 & 90 & 125 & 15 & 50 & 90 & \\
\hline Calcite encrusting layer & $42.0(14.9)$ & $22.5(22.8)$ & & & $32.5(15.4)$ & $2.8(5.0)$ & & \\
\hline Coralline algae & & & & & $12.6(10.7)$ & $0.4(1.3)$ & & 80300934 \\
\hline Sponges & & & $1.2(2.7)$ & & & $5.2(9.1)$ & $50.0(17.0)$ & 10000921 \\
\hline Filamentous mat & & & $51.8(14.0)$ & $65.4(27.9)$ & & & $14.7(21.9)$ & \\
\hline \multicolumn{9}{|l|}{ Hard corals } \\
\hline Tubastrea sp. 1 & $0.8(1.7)$ & & & & $6.5(10.0)$ & & & 11290901 \\
\hline Tubastrea sp. 2 & 24.1 (15.3) & $10.5(9.5)$ & & & $22.2(15.3)$ & $45.6(14.3)$ & & 11290901 \\
\hline Pocillopora sp. & $12.7(13.5)$ & & & & $19.7(13.9)$ & $2.4(7.6)$ & & 11290912 \\
\hline Unidentified & & $0.5(1.6)$ & & & $6.5(10.9)$ & $6.4(14.0)$ & $3.7(5.6)$ & \\
\hline \multicolumn{9}{|l|}{ Soft corals } \\
\hline Scleronephthya sp. 1 & $12.5(14.8)$ & $51.4(14.3)$ & & & & & & 11168911 \\
\hline Scleronephthya sp. 2 & & & $39.3(14.0)$ & $19.9(30.8)$ & & $0.4(1.3)$ & $0.3(1.2)$ & 11168911 \\
\hline Nephthea sp. & $3.3(10.5)$ & $7.8(14.1)$ & $0.8(1.7)$ & $0.4(1.3)$ & & $19.2(18.8)$ & & 11168911 \\
\hline Unidentified & & & $1.9(2.7)$ & $8.5(10.1)$ & & & & 11168909 \\
\hline \multicolumn{9}{|l|}{ Others } \\
\hline True anemones & & & & & & $17.6(20.3)$ & $30.2(19.1)$ & 11229903 \\
\hline Total bryozoan/hydroids & $4.2(10.2)$ & $7.3(15.3)$ & $5.1(9.6)$ & $5.6(7.4)$ & & & & 20 000905/11001000 \\
\hline
\end{tabular}
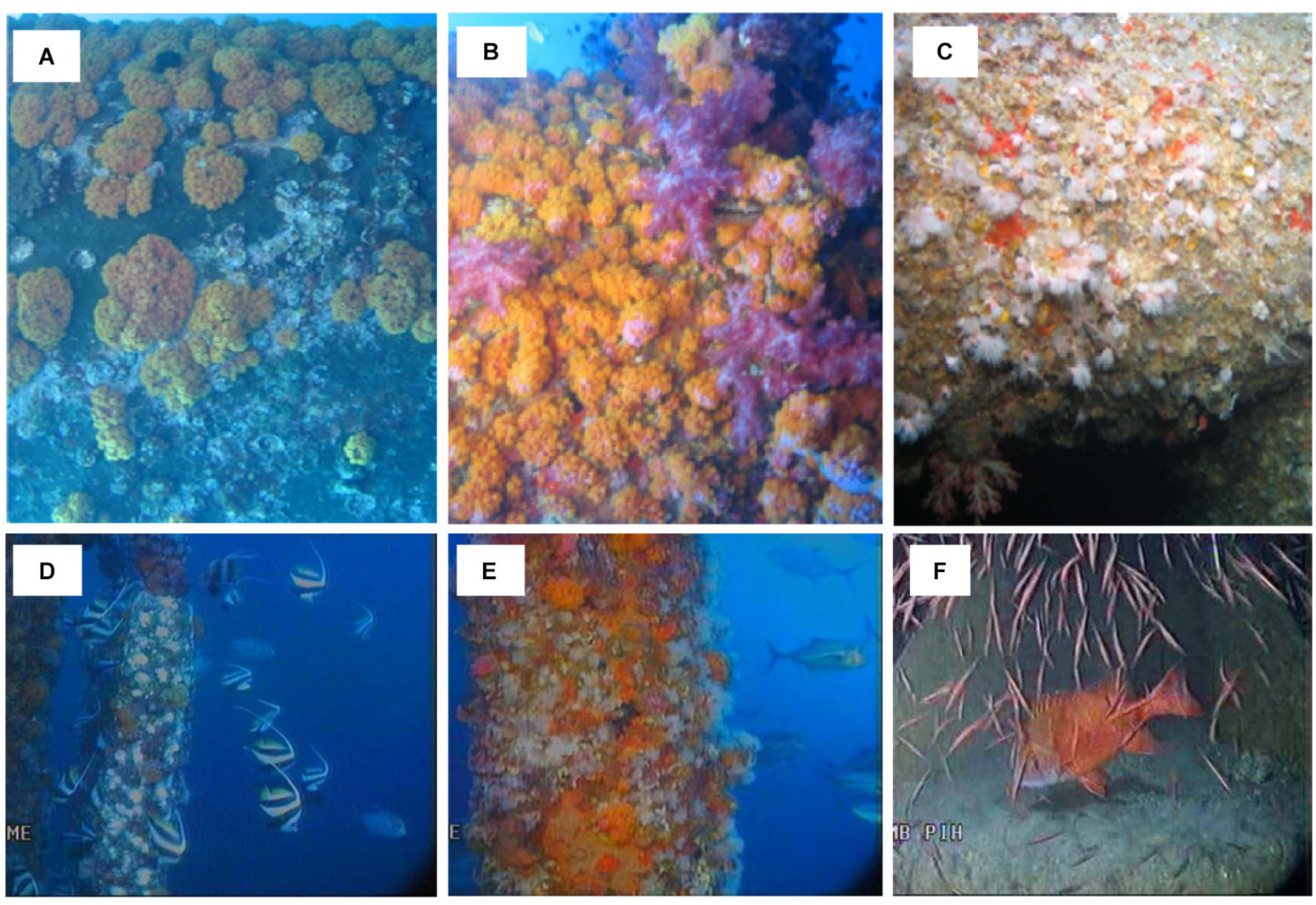

FIGURE 2 | Attached invertebrates on Goodwyn Alpha platform and associated fishes, including (A) the white calcite encrusting layer with bleached bivalves and the hard coral Tubastrea sp. 2, (B) the soft coral Nephthea spp. with the orange hard coral Tubastrea sp. 2, (C) true anemones, sponges and the filamentous layer, (D) bannerfish (Heniochus sp.), (E) trevally (Caranx spp.) and (F) a school of unidentified juvenile fish and a red emperor (Lutjanus sebae). 
A

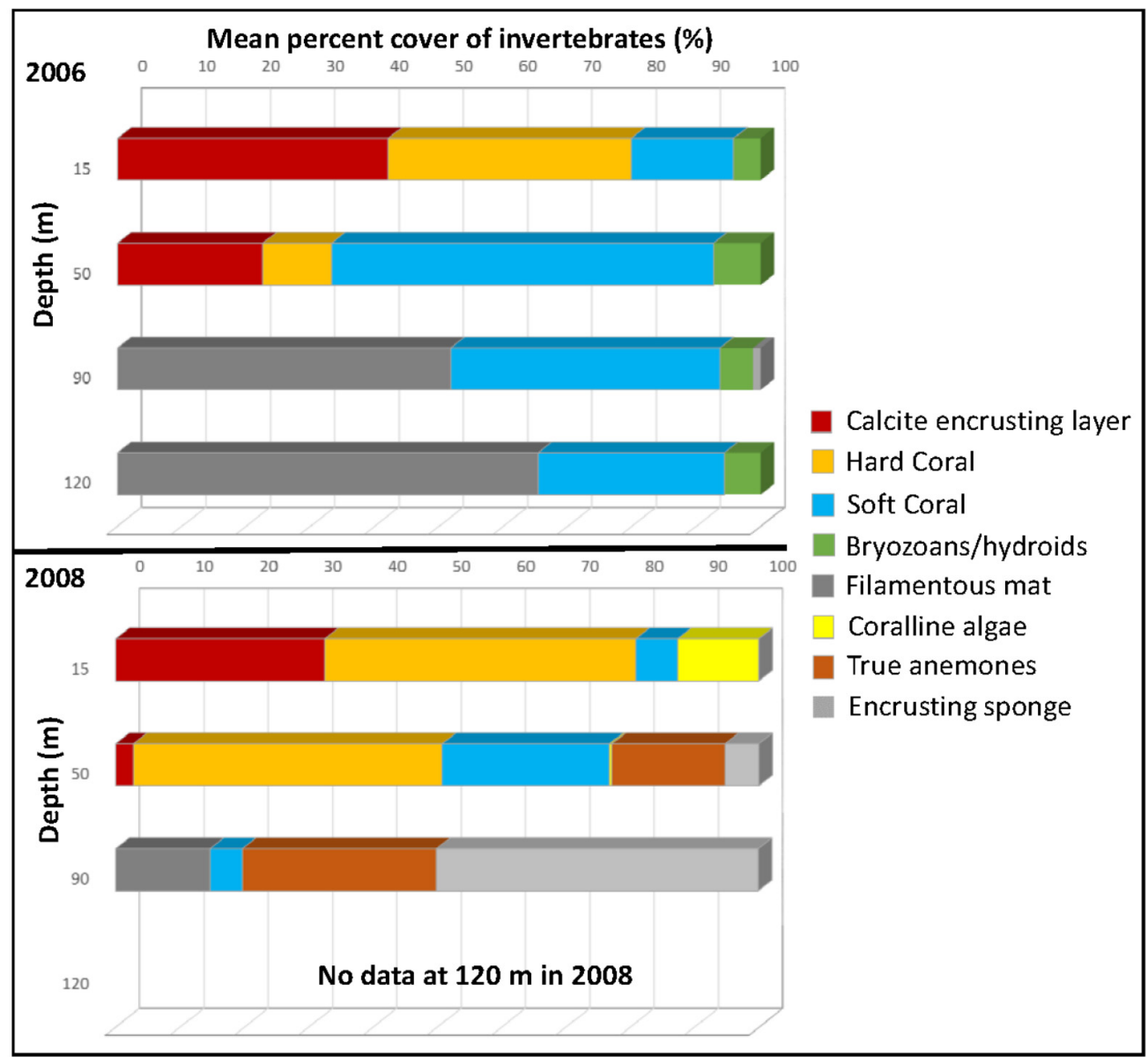

B

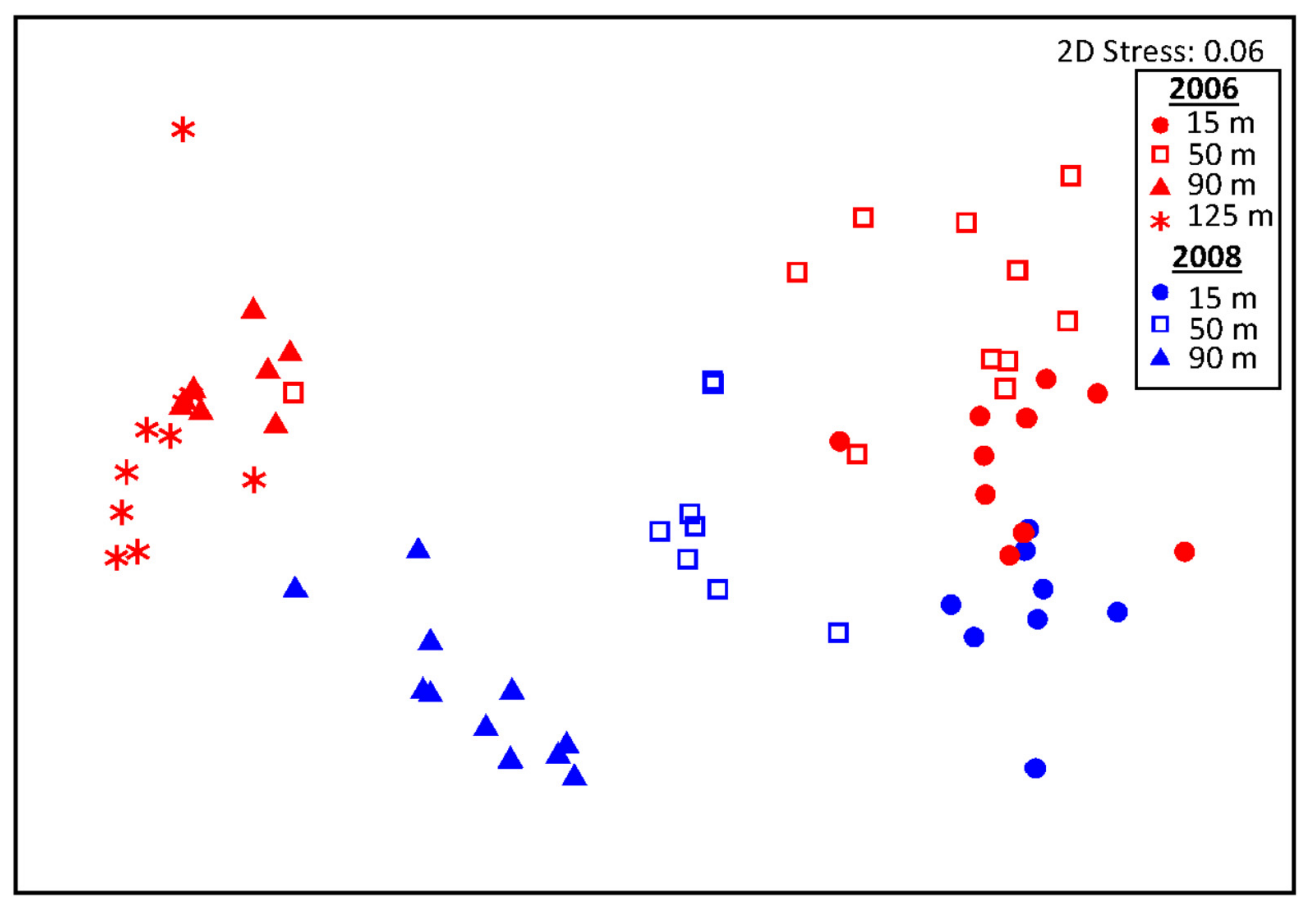

FIGURE 3 | Sessile attached invertebrate coverage and changes in coverage with depth and between years illustrated by (A) mean percent cover by the major invertebrate taxa/groups and (B) multidimensional scaling plot (MDS) of the sessile invertebrate species on the horizontal members of Goodwyn Alpha platform in 2006 and 2008. In the MDS, each data point represents a replicate quadrat. The MDS is constructed from Bray-Curtis similarities based on the percent coverage of different groups/species. There was no footage available for analysis of the sessile invertebrates from $125 \mathrm{~m}$ in 2008. 
group which were present over all depths at $\leq 7.3 \%$ coverage (Table 1).

The percent coverage of the sessile invertebrate community differed significantly among depths in 2006 (PERMANOVA: pseudo- $F=31.461, P=0.0001)$. Pairwise comparisons between progressive depths indicated that the community differed between depths of $15 \mathrm{~m}, 50 \mathrm{~m}$, and $90 \mathrm{~m}$. The community coverage between 15 and $50 \mathrm{~m}$ was significantly different (pairwise PERMANOVA, pseudo- $t=2.6, P=0.0007$ ), primarily due to an increase in coverage of Scleronephthya sp. 1 and a decrease in the coverage of the calcite layer and the hard corals Tubastrea sp. 2 and Pocillopora sp. which together contributed 79\% of the dissimilarity between depths (SIMPER, Table 2). Community coverage did not differ between 90 and $125 \mathrm{~m}$ (pseudo- $t=1.2905, P=0.2345$ ). However, the community at 90 and $125 \mathrm{~m}$ differed considerably from that at $50 \mathrm{~m}$ (PERMANOVA: 50 vs. $90 \mathrm{~m}$, pseudo- $t=6.2183, P=0.0001$; 50 vs. $125 \mathrm{~m}$, pseudo- $t=5.2418, P=0.0001)$. The difference in communities between 50 and $90 \mathrm{~m}$ was primarily due to the increase in coverage of the filamentous mat and the decrease in coverage of the soft coral Scleronephthya sp. 1 at $90 \mathrm{~m}$, together contributing $47 \%$ of the dissimilarity between depths (Table 2).
An increase in the cover of Scleronephthya sp. 2, a decrease in the cover of the calcite layer and a decrease in the hard coral Tubastrea sp. 2 at $90 \mathrm{~m}$ contributed to the remaining dissimilarity of $88 \%$.

A similar pattern of community change across depth was observed in 2008 (Figures 3A,B and Table 1). Overall, at $15 \mathrm{~m}$, coverage was dominated by hard corals at 54.9\% (mostly Tubastrea sp. 2 and Pocillopora sp. at $22.2 \%$ and $19.7 \%$, respectively) and the calcite layer (32.5\%). At $50 \mathrm{~m}$, the hard corals (mostly Tubastrea sp. 2, 45.6\%), the soft coral Nephthea sp. (19.2\%), and the anemones (17.6\%) predominated. At $90 \mathrm{~m}$, coverage was dominated by sponges (50.0\%), anemones $(30.2 \%)$ and filamentous mat (14.7\%). Bryozoans/hydroids were apparently absent at any depth in 2008.

Community coverage differed significantly among depths in 2008 (PERMANOVA: pseudo- $F=39.897, P=0.0001$ ) (Figures 3A,B). Like 2006, pairwise comparisons confirmed community differences between each adjacent depth zone. The community coverage at $15 \mathrm{~m}$ and $50 \mathrm{~m}$ was significantly different (PERMANOVA: pseudo- $t=4.6912, P=0.0002$ ), due primarily to a decrease in coverage by the calcite layer which contributed most the dissimilarity between depths (18.8\%; Table 2). Otherwise, a

TABLE 2 | Percent mean cover and Similarity Percentage results (SIMPER) for sessile invertebrates contributing up to $80 \%$ of the dissimilarity in coverage between adjacent depths on the Goodwyn Alpha platform in 2006 and 2008.

\begin{tabular}{|c|c|c|c|c|c|c|}
\hline \multirow[t]{2}{*}{ Year } & \multirow[t]{2}{*}{ Depth comp } & \multirow[t]{2}{*}{ Group/Taxa } & \multicolumn{2}{|c|}{$\%$ mean cover at depth } & \multirow[t]{2}{*}{ Contribution to dissimilarity $\%$} & \multirow[t]{2}{*}{ Cumulative $\%$ contribution } \\
\hline & & & $15 \mathrm{~m}$ & $50 \mathrm{~m}$ & & \\
\hline \multirow[t]{16}{*}{2006} & 15 vs. 50 m & Scleronephthya sp. 1 - SC & 12.5 & 51.4 & 27.01 & 27.01 \\
\hline & & Calcite encrusting layer & 42.0 & 22.5 & 19.61 & 46.62 \\
\hline & & Tubastrea sp. 2 - HC & 24.1 & 10.5 & 16.48 & 63.1 \\
\hline & & Pocillopora sp. - HC & 12.7 & 0 & 16.01 & 79.12 \\
\hline & & Nephthea sp. - SC & 3.3 & 7.8 & 9.39 & 88.51 \\
\hline & & & $50 \mathrm{~m}$ & $90 \mathrm{~m}$ & & \\
\hline & 50 vs. 90 m & Filamentous mat & 0 & 51.8 & 24.14 & 24.14 \\
\hline & & Scleronephthya sp. 1 - SC & 51.4 & 0 & 23.1 & 47.24 \\
\hline & & Scleronephthya sp. 2 - SC & 0 & 39.3 & 19.81 & 67.06 \\
\hline & & Calcite encrusting layer & 22.5 & 0 & 12.29 & 79.35 \\
\hline & & Tubastrea sp. 2 - HC & 10.5 & 0 & 8.18 & 87.52 \\
\hline & & & $90 \mathrm{~m}$ & $125 \mathrm{~m}$ & & \\
\hline & 90 vs. 125 m & Scleronephthya sp. 2 - SC & 39.3 & 19.3 & 43.57 & 43.57 \\
\hline & & Filamentous mat & 51.8 & 65.4 & 23.76 & 67.33 \\
\hline & & Unidentified - SC & 1.9 & 8.5 & 19.13 & 86.46 \\
\hline & & & $15 \mathrm{~m}$ & $50 \mathrm{~m}$ & & \\
\hline \multirow[t]{11}{*}{2008} & 15 vs. 50 m & Calcite encrusting layer & 32.5 & 2.8 & 18.83 & 18.83 \\
\hline & & Pocillopora sp. - HC & 19.7 & 2.4 & 14.97 & 33.8 \\
\hline & & Nephthea sp. - SC & 0 & 19.2 & 14.58 & 48.39 \\
\hline & & True anemones & 0 & 17.6 & 11.93 & 60.31 \\
\hline & & Coralline algae - Enc & 12.6 & 0.4 & 10.82 & 71.14 \\
\hline & & Tubastrea sp. 2 - HC & 22.2 & 45.6 & 10.19 & 81.33 \\
\hline & & & $50 \mathrm{~m}$ & $90 \mathrm{~m}$ & & \\
\hline & 50 vs. 90 m & Tubastrea sp. 2 - HC & 45.6 & 0 & 27.77 & 27.77 \\
\hline & & Sponge - Enc & 5.2 & 50.0 & 22.88 & 50.65 \\
\hline & & Nephthea sp. - SC & 19.2 & 0 & 15.4 & 66.05 \\
\hline & & True anemones & 17.6 & 30.2 & 13.69 & 79.74 \\
\hline
\end{tabular}

SC, soft coral; HC, hard coral. 
decrease in coverage by Pocillopora sp. and coralline algae and an increase in coverage by Nephthea sp., anemones and Tubastrea sp. 2 at $50 \mathrm{~m}$ compared to $15 \mathrm{~m}$ contributed between 10 and $15 \%$ each of the remaining dissimilarity between the two depths. Percent coverage by groups again changed significantly between the 50 and $90 \mathrm{~m}$ depths (PERMANOVA: pseudo- $t=5.8171$, $P=0.0001)$. The decrease in Tubastrea sp. 2 and Nephthea sp. at $90 \mathrm{~m}$ contributed $43.2 \%$ of this dissimilarity with a further $36.6 \%$ of dissimilarity explained by an increase in cover of sponges and anemones at that depth.

We found a substantial change in the percent coverage of the attached invertebrates between years (PERMANOVA: pseudo$F=4.883, P=0.0002$ ) (Figures 3A,B). Overall, this change was evident in the decrease in soft corals and bryozoans/hydroids at all depths and a general increase in cover by hard coral, sponges and true anemones in 2008 (Table 3 and Figure 3A). The community at $15 \mathrm{~m}$ differed significantly between years (PERMANOVA: pseudo- $t=2.4481, P=0.0003$ ) and was due to changes in several groups/species contributing similar percentages to the dissimilarity (between 10 and 19\%, Table 3). Taxa with greater coverage in 2008 at $15 \mathrm{~m}$ included coralline algae and the hard corals, Pocillopora sp. and Tubastrea sp. 1. Those with less coverage in 2008 included Scleronephthya sp. 1, Tubastrea sp. 2 and the calcite layer. Coverage also differed between years at $50 \mathrm{~m}$ depth (PERMANOVA: pseudo- $t=3.9192$, $P=0.0001)$. At this depth, a large decrease in the mean coverage by the soft coral Scleronephthya sp. 1 (which was not observed in 2008) contributed $26.7 \%$ to the dissimilarly between years, along with a decrease in the calcite layer coverage which accounted for a further $13 \%$ of dissimilarity (Table 3). Large increases in mean cover of Tubastrea sp. 2, Nephthea sp. and anemones contributed $18.2 \%, 14.2 \%$, and $12.8 \%$, respectively, to the remaining dissimilarity between years at $50 \mathrm{~m}$ depth. Finally, the invertebrate coverage also differed between years at $90 \mathrm{~m}$ (PERMANOVA: pseudo- $t=9.0934, P=0.0001$ ). The large increase in coverage of sponges and anemones during 2008 contributed $45.0 \%$ of dissimilarity between years, whilst the apparent disappearance of bryozoans/hydroids and the decrease of the filamentous mat contributed $23.3 \%$ and $19.2 \%$, respectively.

\section{Fishes}

We identified and counted 1791 individual fish from at least 10 families and 19 species (Table 4 and Figures 2D-F). Where fish could not be identified to species, they were grouped into broader categories; 'small cryptic fish' included those fish sheltering in marine growth cover, and 'baitfish' were those found only at the maximum depth and in large schools. Some fish species could not be reliably distinguished from each other and were grouped together, such as the genera of the unidentified surgeonfish and unicornfish and the bluefin/bigeye trevally (Caranx melampygus or C. sexfasciatus) which at times could not be distinguished from each other due to varying light levels and speed of movement.

In 2006, abundance and diversity of fish were low, with only 119 individuals from at least six families observed (Table 4). Mean fish densities ranged between $8 \mathrm{fish} / 50 \mathrm{~m}^{2}$ in the upper water column to a maximum of $14 \mathrm{fish} / 50 \mathrm{~m}^{2}$ in the 25$100 \mathrm{~m}$ depth category, but we found no significant difference in total fish density among depths (ANOVA, $F_{2,7}=0.06769$, $P=0.9351$ ). Unidentified surgeonfish (Acanthurus spp.) and false bluefin trevally (Carangoides orthogrammus) were most abundant between 10 and $25 \mathrm{~m}$, reaching 5.1 and 1.3 fish per

TABLE 3 | Dissimilarity and percent mean cover of attached invertebrates between depths in 2006 and 2008.

\begin{tabular}{|c|c|c|c|c|c|}
\hline \multirow[t]{2}{*}{ Depth (m) } & \multirow[t]{2}{*}{ Group/Taxa } & \multicolumn{2}{|c|}{$\%$ mean cover } & \multirow[t]{2}{*}{ Contribution to dissimilarity $\%$} & \multirow[t]{2}{*}{ Cumulative $\%$ contribution } \\
\hline & & 2006 & 2008 & & \\
\hline \multirow[t]{7}{*}{15} & Scleronephthya sp. 1 - SC & 12.5 & 0 & 18.59 & 18.59 \\
\hline & Coralline algae - Enc & 0 & 12.6 & 18.22 & 36.81 \\
\hline & Pocillopora sp. - HC & 12.7 & 19.7 & 16.12 & 52.93 \\
\hline & Tubastrea sp. 2 - HC & 24.1 & 22.1 & 13.96 & 66.89 \\
\hline & Tubastrea sp. 1 - HC & 0.8 & 6.5 & 10.46 & 77.35 \\
\hline & Calcite encrusting layer & 42.0 & 32.5 & 10.09 & 87.44 \\
\hline & & 2006 & 2008 & & \\
\hline \multirow[t]{6}{*}{50} & Scleronephthya sp. 1 - SC & 51.4 & 0 & 26.71 & 26.71 \\
\hline & Tubastrea sp. 2 - HC & 10.5 & 45.6 & 18.18 & 44.89 \\
\hline & Nephthea sp. - SC & 7.8 & 19.2 & 14.19 & 59.08 \\
\hline & Calcite encrusting layer & 22.5 & 2.8 & 13.41 & 72.49 \\
\hline & Anemone & 0 & 17.6 & 12.84 & 85.33 \\
\hline & & 2006 & 2008 & & \\
\hline \multirow[t]{4}{*}{90} & Sponges & 1.2 & 50.0 & 25.58 & 25.58 \\
\hline & Bryozoans/hydroids & 5.1 & 0 & 23.3 & 48.87 \\
\hline & Anemone & 0 & 30.2 & 19.31 & 68.18 \\
\hline & Filamentous mat & 51.8 & 14.7 & 19.24 & 87.42 \\
\hline
\end{tabular}

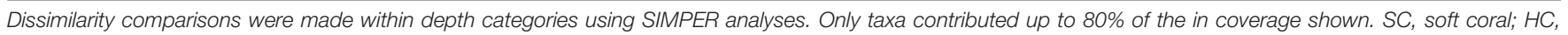
hard coral. 
$50 \mathrm{~m}^{2}$, respectively. Almaco jack (Seriola rivoliana) were the most abundant fish in depths $>25 \mathrm{~m}$ (reaching 9.1 per $50 \mathrm{~m}^{2}$ ) and contributed $80 \%$ of the total fish observed in that year, although they were not observed in 2008. Other fish present in 2006 but not observed in 2008 were a unicornfish, a tallfin batfish (Platax teira) and a giant moray (Gymnothorax javanicus) which was observed sheltering under a jacket anode.

In 2008, we observed 1671 fish from at least 8 families and 16 species (Table 4). Total fish density increased significantly with depth in 2008, from a total of $22.6 \mathrm{fish} / 50 \mathrm{~m}^{2}$ at $10-25 \mathrm{~m}$ to $3373.6 \mathrm{fish} / 50 \mathrm{~m}^{2}$ at $125 \mathrm{~m}$ (ANOVA, $F_{3,12}=56.529$, $P<0.001)$. Density at $125 \mathrm{~m}$ was significantly greater than all other depths (Tukey's tests, all $P<0.001$ ), however, patterns among other depths were less distinct. Total fish density at $10-25 \mathrm{~m}$ was significantly lower than that at 25$50 \mathrm{~m}$ (100.8 fish/50 $\mathrm{m}^{2}$, Tukey's test, $\left.P=0.034\right)$, but densities at $10-25 \mathrm{~m}$ did not differ from 50 to $75 \mathrm{~m}$ (87.5 fish/50 $\mathrm{m}^{2}$, Tukey's test, $\left.P=0.108\right)$. There was also no difference in fish density between 25-50 and 50-75 m (Tukey's test, $P=0.881)$.

There were also significant differences in fish community composition across the depth categories in 2008 (PERMANOVA, pseudo- $\left.F_{3,12}=5.8658, P=0.001\right)$. Unlike fish density, we found there was no significant difference in the community composition of fishes between the $10-25 \mathrm{~m}$ and the $25-50 \mathrm{~m}$ (PERMANOVA, pseudo- $t=1.2349, P=0.372$ ), or between the 25-50 $\mathrm{m}$ and 50-75 $\mathrm{m}$ depth categories (PERMANOVA, pseudo$t=1.5156, P=0.156)$. However, community composition differed significantly between 10-25 $\mathrm{m}$ and 50-75 m (PERMANOVA, pseudo- $t=2.1163, P=0.018)$. All upper depth categories $(\leq 75$ $\mathrm{m})$ also differed significantly in community composition with the 125 m community (PERMANOVA, pseudo- $t \geq 2.3472$, all $P \leq 0.028)$.

TABLE 4 | Fish taxa and mean densities (fish/50 $\mathrm{m}^{2}$ ) identified over three to four depth categories between 10 and 125 m on Goodwyn Alpha platform in 2006 and 2008 .

\begin{tabular}{|c|c|c|c|c|c|c|c|c|c|}
\hline \multirow{2}{*}{\multicolumn{3}{|c|}{ Depth category (m) }} & \multicolumn{3}{|c|}{2006} & \multicolumn{4}{|c|}{2008} \\
\hline & & & $10-25$ & $25-100$ & $100-125$ & $10-25$ & $25-50$ & $50-75$ & 125 \\
\hline \multicolumn{3}{|c|}{ Transect length $(\mathrm{m})$ (all replicates) } & 41 & 51 & 54 & 38 & 55 & 54.3 & + \\
\hline \multicolumn{3}{|c|}{ Transect area $\left(\mathrm{m}^{2}\right)$ (all replicates) } & 118 & 184 & 192 & 176 & 190 & 393 & 14 \\
\hline Family & Genus and species & Common name & & & & & & & \\
\hline Carangidae & Seriola rivoliana & Almaco jack & & $8.9(10.3)$ & $9.1(6.2)$ & & & & \\
\hline Carangidae & $\begin{array}{l}\text { Carangoides } \\
\text { orthogrammus }\end{array}$ & False bluefin trevally & $1.3(1.4)$ & & $0.5(0.8)$ & $5.5(5.6)$ & $2.4(2.6)$ & & \\
\hline Carangidae & $\begin{array}{l}\text { Caranx sexfasciatus or } \\
\text { Caranx melampygus }\end{array}$ & Bluefin/bigeye trevally & & & & $2.2(3.8)$ & $49.7(77.0)$ & $19.4(25.9)$ & \\
\hline Lutjanidae & Lutjanus argentimaculatus & Mangrove jack & & & & $0.2(0.3)$ & & $0.1(0.1)$ & \\
\hline Lutjanidae & Lutjanus erythropterus & Crimson sea perch & $0.5(0.8)$ & $0.6(1.3)$ & $0.2(0.4)$ & & $0.5(1.0)$ & $0.6(0.7)$ & \\
\hline Lutjanidae & Lutjanus bohar & Red bass & & & & & $1.4(1.5)$ & $0.1(0.2)$ & $27.3(28.1)$ \\
\hline Lutjanidae & Lutjanus sebae & Red emperor & & & & & & $0.4(0.8)$ & $5.0(11.2)$ \\
\hline Lutjanidae & Lutjanus malabaricus & Saddle-tailed sea perch & & & & $0.4(0.6)$ & & $0.1(0.1)$ & \\
\hline Serranidae & Cephalopholis sonnerati & Tomato cod & & & & & & $0.3(0.6)$ & \\
\hline Serranidae & Pseudanthias rubrizonatus & Red-bar anthias & & & & & & & $350.0(651.9)$ \\
\hline Chaetodontidae & Heniochus diphreutes & Schooling bannerfish & & $3.1(3.2)$ & $0.9(1.0)$ & & $31.0(21.9)$ & $51.0(26.9)$ & \\
\hline Acanthuridae & Acanthurus spp. & Unidentified surgeonfish & $5.1(4.5)$ & & & $3.2(1.3)$ & $3.9(1.4)$ & $0.6(0.1)$ & \\
\hline Acanthuridae & Acanthurus dussumieri & Ornate surgeonfish & & $0.3(0.6)$ & & & & $0.7(0.1)$ & \\
\hline Acanthuridae & Naso hexacanthus & Sleek unicornfish & & & & & $1.3(2.5)$ & & \\
\hline Acanthuridae & Naso spp. & Unicornfish & $0.5(0.8)$ & & & & & & \\
\hline Apogonidae & Apogon sp. & Cardinalfish & & & & & & & $436.7(736.6)$ \\
\hline Pomacanthidae & Pomacanthus imperator & Emperor angelfish & & $0.3(0.6)$ & & & $0.3(0.5)$ & & \\
\hline Monacanthidae & Unknown & Filefish unidentified & & & & & & $0.4(0.8)$ & \\
\hline Ephippidae & Platax teira & Tall-fin batfish & $0.5(0.8)$ & & & & & $0.4(0.4)$ & \\
\hline \multirow[t]{4}{*}{ Muraenidae } & Gymnothorax javanicus & Giant moray & & $0.4(0.9)$ & & & & & \\
\hline & & Shark unidentified & & & & $0.4(0.6)$ & & & \\
\hline & & Small cryptic fish & $0.4(0.6)$ & $0.1(0.3)$ & & $10.9(11.1)$ & $10.3(11.0)$ & $14.0(26.7)$ & \\
\hline & & Baitfish & & & & & & & $2554.7(2164.6)$ \\
\hline \multicolumn{3}{|c|}{ Total density depth category $\left(50 \mathrm{~m}^{2}\right)$} & 8.1 & 13.7 & 10.7 & 22.6 & 100.8 & 87.5 & 3373.6 \\
\hline \multicolumn{3}{|c|}{ Standard deviation } & 4.34 & 6.81 & 5.94 & 11.27 & 49.53 & 52.71 & 1397.55 \\
\hline
\end{tabular}

Standard deviation shown in brackets. ${ }^{+}$indicates snapshots of infrastructure at $125 \mathrm{~m}$ where transect footage was unavailable. 
SIMPER analysis described the species/groups that contributed most to the similarities within depths and significant dissimilarities between depths during 2008 (Table 5a,b). The community at $0-25 \mathrm{~m}$ was characterized by small cryptic fish, false bluefin trevally and unidentified surgeonfish, with the former two groups having mean densities of 10.9 and $5.5 \mathrm{fish} / 50 \mathrm{~m}^{2}$, respectively, and accounting for $80.1 \%$ of the similarity at this depth (Table 5a). The community at 25-50

TABLE 5 | (a) Mean densities of fish taxa that contributed to similarities of each depth category according to SIMPER analysis, and (b) fish taxa that contributed to dissimilarities between depths where significant differences were found.

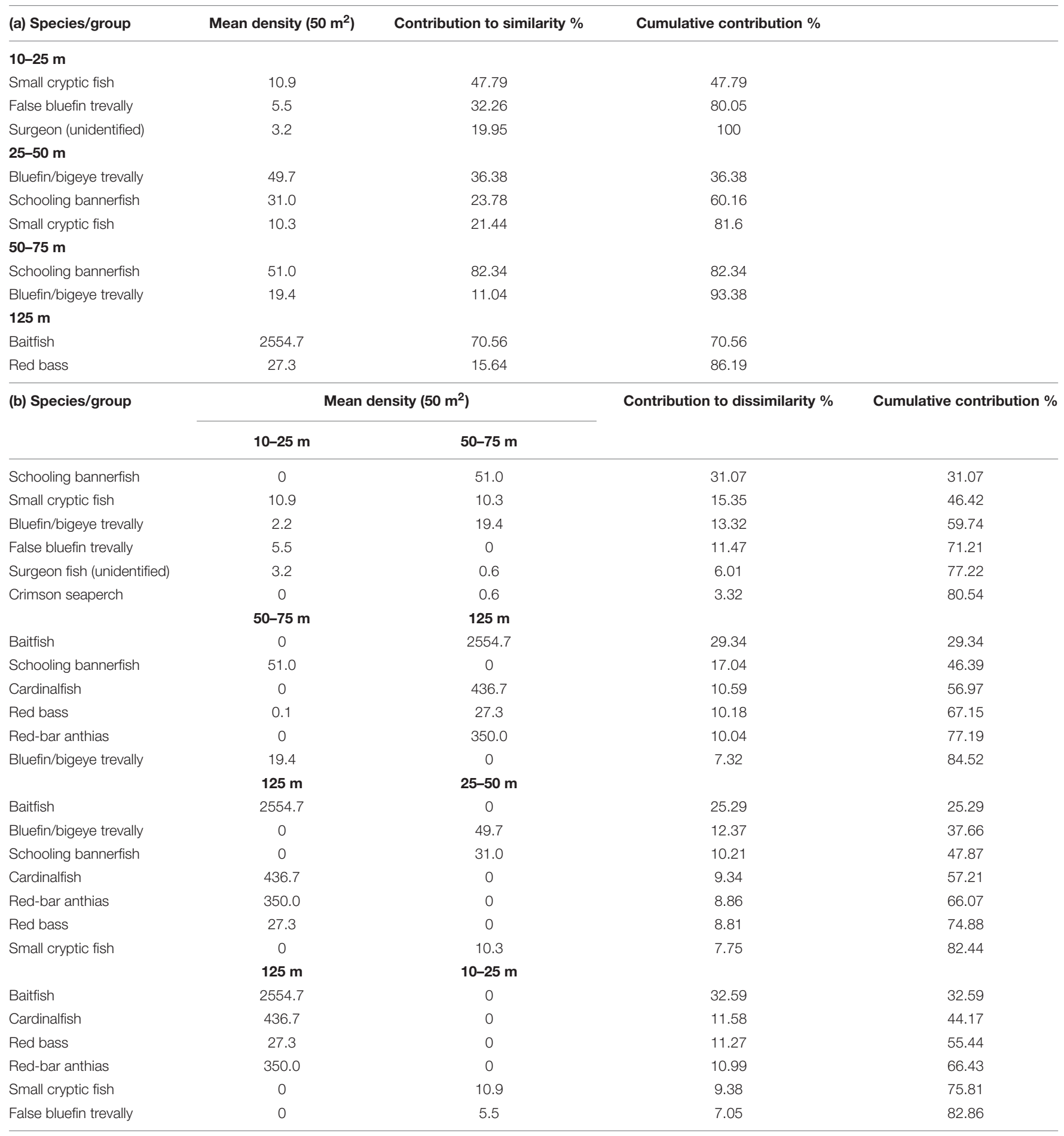

Only taxa contributing up to at least $80 \%$ are shown. 
m was dominated by bluefin/bigeye trevally and schooling bannerfish (Heniochus diphreutes), with mean densities of 49.7 and $31.0 \mathrm{fish} / 50 \mathrm{~m}^{2}$, respectively. Along with the small cryptic fish, these taxa accounted for $81.6 \%$ of the similarity at this depth. Between 50 and $75 \mathrm{~m}$, schooling bannerfish reached 51.0 fish/50 $\mathrm{m}^{2}$ and accounted for $82.3 \%$ similarity within the depth category and bluefin/bigeye trevally were again in high density at this depth, reaching $19.4 \mathrm{fish} / 50 \mathrm{~m}^{2}$. The significant difference in the fish communities between 10-25 $\mathrm{m}$ and 50-75 $\mathrm{m}$ (reported above) was due to greater density of the schooling bannerfish and the bluefin/bigeye trevally (31.1\% and $13.3 \%$ contribution to dissimilarity) (Table 5b) and lower density of the small cryptic fishes and false bluefin trevally (15.4\% and $11.5 \%$, respectively) at 50-75 m.

At $125 \mathrm{~m}$, the community was typified by baitfish and red bass (Lutjanus bohar) which contributed $70.6 \%$ and $15.6 \%$, respectively, of the similarity within the depth category (Table 5a). Baitfish were found exclusively at this depth and at a high mean density of 2554.7 fish/50 $\mathrm{m}^{2}$. Red-bar anthias (Pseudanthias rubrizonatus) and cardinalfish (Apogon sp.) were also found only at this depth and in high densities (350.0 and $436.7 \mathrm{fish} / 50 \mathrm{~m}^{2}$, respectively, Table 5b). SIMPER analysis indicated that the significant differences in fish composition between $125 \mathrm{~m}$ and all other depth categories (reported above) were largely due to these taxa that were specific to this depth (Table 5b). Baitfish contributed up to $32.6 \%$ dissimilarity while red-bar anthias (P. rubrizonatus) and cardinalfish (Apogon sp.) contributed up to $22.6 \%$ dissimilarity combined. Bluefin/bigeye trevally and schooling bannerfish were also important contributors to the differences between the $125 \mathrm{~m}$ category and all others, being present in relatively high densities at shallower depths but not recorded at $125 \mathrm{~m}$.

\section{DISCUSSION}

To our knowledge, this is the first published study of attached invertebrate species and fish communities associated with an operational oil and gas platform on Australia's North West Shelf. Furthermore, this study provides an insight into the usefulness of archival industry ROV footage for assessing marine communities associated with oil and gas structures.

Although not collected for scientific purposes, archived ROV inspection footage is a potentially valuable resource for environmental science as the footage incidentally captures flora and fauna associated with oil structures during inspections. The operator's video archive, for example, contains footage of infrastructure since its establishment in 1995, with multiple visits to the same structures over extended time periods. Some footage dates back to the 1970s, potentially providing rare longterm datasets from an offshore environment that is challenging to study independently. Specific structures on the platform are easily identified and can be revisited over many years, allowing for fine scale studies of biological communities at specific points. Furthermore, footage is available from a range of subsea infrastructure including platforms, risers, pipelines and wellheads at a variety of depths over wide geographical ranges under the influence of different oceanographic regimes. Industrycollected footage may therefore provide an important tool for assessing the biodiversity associated with oil structures, how this diversity may change over time, how infrastructure functions as an artificial reef, and how communities on infrastructure interact with surrounding marine ecosystems. Despite some limitations using industry-collected ROV footage (outlined below), we were able to: (1) broadly identify the major elements of the invertebrate community inhabiting the GWA platform and estimate their coverage on horizontal members; (2) identify changes in the attached community with depth and time, and (3) identify differences in fish density and distribution with depth. It is important to note that our data are meant to illustrate the potential usefulness of $\mathrm{ROV}$ archival footage, rather than a comprehensive attempt to assess long term temporal trends on and around this platform.

\section{Attached Invertebrate Communities}

Sessile invertebrates could only be placed into broad taxonomic categories, mostly due to the poor resolution of the video. Despite this issue, we were able to determine patterns of community composition with depth along the platform and between the years using data obtained from the industry footage.

It appeared that at least some of the factors affecting depth zonation and community composition of sessile communities on natural reefs, including light availability, prey, competition, and habitat characteristics (Karlson and Cornell, 1998), also influenced their distribution on GWA. On the platform, we found autotrophic species mostly limited to $50 \mathrm{~m}$ depth, most likely reflecting light availability necessary for photosynthesis. These included the coralline algae, the hard coral Pocillopora sp. and the soft corals. The exception was the soft coral Scleronephthya sp. 2 which was unusual in its deeper distribution from $50 \mathrm{~m}$ depth, indicating this species requires less light and/or was an azooxanthellate species.

In contrast, heterotrophic species were distributed across all depths. The most significant heterotrophs in terms of surface cover in the upper $50 \mathrm{~m}$ of the platform were the bivalves within the calcite encrusting layer. Whilst indistinct in the video, this community appeared to be largely comprised of both living and bleached bivalve shells. Bivalves are common on platforms and large numbers have been previously observed on platforms in the North Sea, the Gulf of Mexico, California coastal waters and on wellheads in the North West Shelf of Western Australia (George and Thomas, 1979; Love et al., 1999; van der Stap et al., 2016; McLean et al., 2018b). The occurrence of these filter feeders on members in the upper $50 \mathrm{~m}$ of the platform likely mirrors the occurrence of their planktonic prey in the upper sunlit layers of the water column.

Other abundant heterotrophs included the two species of Tubastrea. These hard corals lack photosynthetic zooxanthellae yet contributed much of the coral cover in the upper $50 \mathrm{~m}$ of the platform in both years. Tubastrea is often found attached to oil and gas platforms in the Gulf of Mexico, West Africa and in the South Atlantic (Friedlander et al., 2014; Sammarco et al., 2015; Creed et al., 2017). At depths $\geq 50 \mathrm{~m}$, heterotrophic species such as sponges, bryozoans, hydroids and anemones with reduced 
light requirements dominated the coverage. Additionally, the filamentous mat was important from 90 to $125 \mathrm{~m}$ depth. Without physical samples, we cannot describe this community further. Based on other platform studies, it is possible that this layer consists of encrusting bryozoans (Forteath et al., 1982), although we could not confirm this from the video footage.

We observed a dramatic change in community composition on the GWA platform where soft corals were largely reduced in cover or lost between 2006 and 2008. Several factors may have caused this change and the most obvious to consider first is jacket cleaning. Removal of attached invertebrates on subsea infrastructure is a semi-regular occurrence necessary to reduce the load exerted against the structure by water currents. However, as the last large scale cleaning event was in 1998 (M. Biczo, pers. comm., 26 August 2013), cleaning was not responsible for the changes we observed. We also discount that biofouling measures impacted the soft corals as the cover of invertebrates we observed would indicate that the antifouling, applied prior to the installation of the platform in 1995, would have previously reached the limit of its effectiveness. It is possible, however, that corrosion of the steel legs may have influenced the change in community composition. Soft corals are known to bioaccumulate metals which can affect their growth and reproduction (Hwang et al., 2018), however, leaching of corrosive metals would likely be gradual and unlikely to cause the severe change in communities we observed over a short period. Natural factors such as predation on and/or disease of soft corals by bacteria, fungus and protozoans (Weil et al., 2015) may also have produced the changes we observed. However, we have no data to support either a role of corrosion or natural impacts in the changes we observed.

The most likely factors that resulted in the changing community composition relate to the oceanography of the NWS and the passage of tropical cyclones. Internal tides or waves are an important and energetic component of the NWS where they are generated by large $(10 \mathrm{~m})$ barotropic tides in contact with the continental shelf break (Holloway, 2001). Internal waves displace little water at the ocean surface but result in very large internal, vertical displacements of water (up to $50 \mathrm{~m}$ ). They can generate strong currents that rapidly oscillate in direction throughout the water column at up to $0.5 \mathrm{~ms}^{-1}$, exerting force on and sometimes damaging oil and gas infrastructure (Bole et al., 1994; Fang and Duan, 2014). The force of these currents is sufficient to physically damage and dislodge soft corals, potentially explaining the decrease in soft coral abundance on the GWA platform between 2006 and 2008 surveys.

Tropical cyclones occur regularly on the NWS between November and April and frequently disrupt oil and gas operations at sea and on land. On natural reefs in shallower water, severe tropical cyclones are important in shaping coral reef communities, and can influence coral cover and species diversity, as well as cause widespread coral mortality (Nott and Hayne, 2001; Beeden et al., 2015). Between August 2006 and December 2008, there were five tropical cyclones on the NWS that disrupted offshore industry activities ${ }^{1}$. Two of these cyclones,

${ }^{1}$ http://www.bom.gov.au/cyclone/history/wa/
Tropical Cyclones Kara and George, were classified as category 4 and 5, respectively, by the Australian Bureau of Meteorology Tropical Cyclone Category System, with category 5 being the most severe ${ }^{2}$. Cyclones cause mixing and cooling throughout the water column to $100 \mathrm{~m}$ depth and the generation of very strong, oscillating near-inertial internal waves, with currents reaching up to $1.5 \mathrm{~ms}^{-1}$ at the bottom, but typically $0.5 \mathrm{~ms}^{-1}$ throughout the entire water column for a period of up to 9 days (Rayson et al., 2015). During the study period, the major difference in the attached communities between years was a decrease in soft coral cover across all depths, especially notable in the two species of Scleronephthya and the loss of other soft attached species such as the foliaceous bryozoans/hydroids. Changes in the sessile invertebrate communities and their biomass due to environmental forcing has also been observed on platforms in the Gulf of Mexico due to seasonal flooding from coastal bays and the Mississippi River (George and Thomas, 1979). Thus, it appears that the invertebrate communities of platforms are dynamic in nature, shaped over time by environmental influences. This dynamism may have implications for the effectiveness of platforms to act as artificial reefs if susceptible invertebrates like soft corals play a functional role in the biological communities associated with platforms.

Compared to other studies on platforms (George and Thomas, 1979; Forteath et al., 1982; Friedlander et al., 2014), we did not identify a diverse invertebrate community. This is likely due at least in part to our reliance on video footage and the inability to collect physical specimens. The resolution of video footage was generally too poor to provide quality close-up images that would be required for identifications to lower taxonomic levels. The footage available for this study and our survey approach may also have some inherent biases. Spatial orientation of platform members can influence colonization and this seems particularly important to bryozoan and coral recruitment as these animals seemingly prefer vertical or diagonal surfaces (Forteath et al., 1982; Clark and Edwards, 1999; Perkol-Finkel et al., 2006). These groups may therefore have been under sampled in our study due to the focus on horizontal members. Furthermore, we surveyed only the north facing Row G surfaces of the platform, which is in the lee of the platform and the prevailing south westerly wind. It is possible that communities on this more sheltered aspect of the platform differed to those on more exposed faces. In targeted future studies, we recommend surveys are designed to take member and jacket orientation into account.

\section{Fish Assemblages}

Knowledge of the fish communities associated with Australia's offshore oil structures is also essential for understanding their habitat value. We observed 1791 fish from at least 19 species and 10 families associating with the GWA platform during the current study. Like other studies in the region on infrastructure (Pradella et al., 2014; McLean et al., 2017, 2018b), we identified commercially important target species in the Pilbara demersal fishery, including crimson seaperch (Lutjanus erythropterus),

\footnotetext{
${ }^{2}$ http://www.bom.gov.au/cyclone/about/intensity.shtml
} 
red emperor (L. sebae), saddle-tailed seaperch (L. malabaricus) and mangrove jack (L. argentimaculatus) (Fletcher and Santoro, 2012). Trevally (Caranx sexfasciatus and C. melampygus) were the most abundant of the commercial and recreational species at GWA and were found in the upper $75 \mathrm{~m}$ in 2008.

The diversity of fishes at GWA was lower than on other infrastructure within a $60 \mathrm{~km}$ radius. Our sampling effort and time of sampling was most similar to Pradella et al. (2014) who used ROV video to count and identify fish at three obsolete well heads at depths of $85-175 \mathrm{~m}$ in June and July 2008. They found 31 species from 14 families, including ten commercially important species. Similarly, McLean et al. (2017) used ROV video to study fish on pipelines between August to December over a 3-year period. This study found 37 species from 21 families on a pipeline at approximately $125 \mathrm{~m}$ depth and 74 species from 30 families on another pipeline at 60-80 $\mathrm{m}$ depth. The cause(s) of differences in fish diversity among these studies and infrastructure types is unknown. It does not appear related to habitat complexity, because the well heads, and to a lesser extent, the platform would have provided the most complex and high relief habitat and the pipelines the least. Sound and vibration from an operating oil and gas platform such as GWA may have some inhibitory effect on some fish species as underwater sound is known to affect their behavior and the abundance of catches (Engås et al., 1996; Normandeau Associates Inc., 2012). An alternative explanation for the relatively low number of taxa recorded in our study is the short duration of the footage examined, conducted over just 2 days in each year which may have underestimated the state of the fish diversity associated with GWA. Examination of footage from other seasons and years would likely result in a broader range of species being detected at the site.

The low fish abundance recorded during 2006 in the current study was most likely due to footage being taken at night. Although ROV lights illuminated the foreground of footage, low light levels in the background likely reduced detection rates of individuals relative to footage taken during the day. Furthermore, the effect of ROV lighting on fish behavior is variable, whilst some fish may be only slightly affected, others may flee the light the approaching ROV (Laidig et al., 2012), so our results may at least partially reflect this effect. Additionally, many fish species are known to exhibit reduced mobility at night, sheltering in crevices, overhangs and within the invertebrate coverage (Nagelkerken et al., 2000). This behavior makes them difficult to detect with remote survey techniques such as video. In contrast, nocturnal feeders increase mobility at night, and may move away from shelter to forage on surrounding substrata during hours of darkness. This may explain the reduced abundance of lutjanid species observed on GWA in 2006 (Table 4), many of which are known to feed at night in areas surrounding their daytime resting sites (Hobson, 1965; Colton and Alevizon, 1981). Seasonal fluctuations in abundance in the study region may also have contributed to the low abundances of fish observed in 2006. Footage in 2006 was taken during late winter (August), whereas footage in 2008 was taken during summer (December). Seasonal investigations which incorporate footage taken during both the day and night are required to identify temporal factors of greatest influence on oil structure communities.

\section{Habitat Value of Structures}

Determining the habitat value of oil and gas structures, and the relative value of different sections within large structures like platforms, is important for evaluating decommissioning options involving partial removal. In the case of the 'topping' option, where the upper steel jacket is removed from the surface to approximately $30 \mathrm{~m}$ depth, some habitat provided by the photosynthetic portion of the attached community will be lost. However, considering the force of waves at the ocean's surface that minimize settlement and growth and the application of antibiofouling strategies employed in the upper $15 \mathrm{~m}$ (Surespek Iss PTY Ltd, 2009), loss of this habitat over $30 \mathrm{~m}$ will likely be minimal. Of possibly greater importance to the habitat value of the jacket of GWA is the continual impact of the passage of cyclones and energetic internal waves on the NWS. If these forces are shaping the attached community through the semi-regular removal of weakly attached species, it may be that the community is not reaching its full habitat potential, unlike the platforms in RTR programs located in more quiescent environments where internal wave energy is quickly dissipated in shallow waters (Rayson et al., 2015). A principle difference between platforms on the NWS shelf and those elsewhere is the occurrence of the strong semidiurnal tides. When the cyclone-induced inertial waves coincide with spring tides, attached communities on structures on the NWS may suffer the additive effect of both forces. It may be that platforms on the NWS are of lower habitat value than those elsewhere because of these impacts.

Alternatively, platforms and other oil structures can be situated where biodiversity is limited and far from the nearest natural reefs. On the NWS for example, mid-shelf to deeper water bottoms are characterized by sandy sediments and muds, often with low biodiversity (McLoughlin and Young, 1985; Lyne et al., 2006). As artificial reefs can create an 'ecological halo' effect up to 15 times the size of the actual structure (Reeds et al., 2018), the biodiversity associated with oil structures such as the GWA platform is likely to remain very high compared to the surrounding benthos, a virtual 'biological oasis' independent of changes in community composition over time. Thus, isolated from the nearest reefs and coastal areas, the sessile invertebrate community we observed on GWA most likely reflects a unique assemblage compared to the diversity of the surrounding marine ecosystem. While the pelagic fish we observed may be indicative of those in the wider environment, other fish may have been recruited to the platform as larvae and will not reflect the surrounding communities. Clearly, more research elsewhere on the NWS is required to understand the habitat value of oil structures in this region.

The increase in fish density with depth on GWA in 2008 suggests deeper sections of the platform have greater habitat value than shallower sections. This result is similar to findings on seven platforms located in Southern California (Martin and Lowe, 2010), and a platform in the northern Gulf of Mexico (Rooker et al., 1997). However, patterns of fish abundance with depth have been found to vary greatly among studies and regions, 
with some studies finding greatest abundance in the shallowest sections of oil structures (Stanley and Wilson, 1997; Dokken et al., 2000). The generality of our finding on GWA is therefore unclear, and further investigation is required to determine whether other platforms on the NWS share similar patterns. We also offer our conclusions concerning depth associations on GWA cautiously, due to the short duration of investigation and the different time-period of observation for the $125 \mathrm{~m}$ depth category (3 months earlier than other depth categories). The high densities of baitfish that drove abundance values at $125 \mathrm{~m}$ may represent seasonal recruitment and/or transient movement that may not represent abundance values during other periods.

Community differences between depths on GWA suggest that sections of greatest habitat value are likely to vary among taxa. Similar to findings on other platforms (Rooker et al., 1997), pelagic species (e.g., Bluefin trevally, C. melampygus) were most abundant at mid-depth sections of the structure. In contrast, depth associations of benthic species were mixed, with some taxa more abundant at mid-depths (e.g., 'small cryptic fishes'), while others were more abundant near the platform base (e.g., red-bar anthias, Pseudanthias rubrizonatus). Mixed patterns for benthic taxa are likely the result of depth preferences or tolerances, and suggest that the prediction of depth associations on other platforms will require knowledge of taxon-specific depth distributions. Depth distributions of reef-associated fishes are one of the most poorly understood ecological aspects of fish communities (Brokovich et al., 2008). Given the deep deployment depths of many oil structures, and the relatively uniform habitat they provide, oil structures may assist scientific understanding of patterns of reef fish distribution with depth.

We found high densities of baitfish in the $125 \mathrm{~m}$ depth category exceeding 2,500 individuals per $50 \mathrm{~m}^{2}$ in three out of five surveys near the platform base, and baitfish were not observed in any other depth category. We termed these as 'baitfish' as we could not determine if they were juveniles of a larger species or the adult stages of a small species. However, this result is consistent with findings of high juvenile or sub-adult abundances on platforms in Southern California, the Gulf of Mexico and on pipelines and wellheads in the region of GWA on the NWS, suggesting that the infrastructure offers suitable habitat for some juvenile fishes (Love et al., 2000; Gallaway et al., 2009; Fowler and Booth, 2012; McLean et al., 2017). Such a conclusion would be unsubstantiated here given the short period of the study, the single platform investigated and our inability to even identify the small fish to family level. However, science-directed studies using industry ROV video on other platforms giving rise to larger datasets would provide vital life history data on fish and on the role of platforms as nurseries and in recruitment. Ideally, such studies would be followed up with direct sampling of fish using traps or nets.

Although not observed in their juvenile stage, the presence of site-attached reef taxa indicates a wide range of species recruited to GWA. Given the isolated location of GWA (outer NWS), and the apparent lack of natural reef in the immediate vicinity (100 km radius), site-attached taxa (e.g., 'small cryptic fishes') most likely settled on the platform following a pelagic larval phase. Our observations of adults of such taxa therefore indicate that GWA provided sufficient habitat for developing and sustaining populations following their recruitment (Fowler and Booth, 2012). The ability of oil structures to provide sufficient habitat for sustaining fish populations is a key aspect of their value as habitat.

\section{Limitations of Industry-Collected ROV Footage}

Despite the potential benefits, some challenges and limitations arose when using industry-collected footage for scientific investigation. The video archiving system used by the operator was complex and necessitated a close partnership with industry engineers and access to platform structural plans. Pre-screening to identify useful footage from structures that were repeatedly filmed through time was labor-intensive. Repeat inspections were irregular in terms of frequency and seasons. It was also difficult to find matching footage of components between years taken at similar times of the day. While time of day was largely inconsequential to the invertebrate surveys, it was likely an important factor in describing the fish community (as outlined above). Poor camera resolution and lighting often hampered our ability to identify the attached invertebrates. Similar to another study using ROV footage (van der Stap et al., 2016), our observations underestimated the biodiversity of the community on the GWA platform. For example, from the video we could not reliably distinguish bivalves in the calcite encrusting layer and we did not observe any nonattached motile invertebrates such as worms, snails, crustaceans, etc. which were likely present. Therefore, use of industry archival ROV footage will be useful as a "rapid assessment" tool for biodiversity, which could then be complemented with targeted specimen collection to ensure high levels of scientific rigor.

\section{CONCLUSION AND RECOMMENDATIONS}

Offshore oil structures have been identified as important habitat for marine organisms in numerous regions of the world. For example, platforms in Southern California are known to support large abundances of overfished rockfish species (Schroeder and Love, 2004; Claisse et al., 2014), and the expansion of oil infrastructure in the northern Gulf of Mexico has been linked to the establishment of a valuable red snapper (Lutjanus campechanus) fishery (Gallaway et al., 2009). These discoveries were the result of extensive research programs spanning decades, and have influenced decommissioning policy and practice in both regions. The recent policy decision to allow 'rigs-to-reefs' conversions of obsolete platforms in California (Assembly Bill $2503,2010)$ was contingent on their importance to rockfish populations.

Oil structures in Australia may provide similar habitat functions to those in other regions, yet almost nothing is known about the biological communities associated with Australia's offshore infrastructure. We have demonstrated that archival ROV 
footage can be used to assess attached invertebrate and fish communities on established offshore platforms, albeit with some limitations in species identification and survey design. Our results indicate that archived ROV footage held by the oil and gas industry is a useful tool for understanding the habitat value of oil and gas infrastructure in Australia. Archival footage also provides a cost-effective means for industry to obtain environmental information on their infrastructure relative to field investigations. Information on the habitat value of oil and gas infrastructure will be essential for informing environmentally sound decommissioning policy in Australia.

Some of the limitations of using industry-collected ROV footage for scientific purposes can be overcome in the future. For example, cameras that provide high resolution video (e.g., 4k) and still frames can be easily fitted to ROVs at a small additional expense. The use of $3 \mathrm{D}$ video which allows for precise measurements of organisms and other objects in the field of view would also be valuable (Macreadie et al., 2018). Additionally, ROV research could be complemented by other survey techniques such as baited remote video, light traps and eDNA to help determine how these structures are used by fish (McLean et al., 2017). Finally, ROV-collected specimens would aid greatly in the identification of attached species and cryptic fish. Research using archival ROV footage must be expanded to other platforms and other types of structures (e.g., well heads, pipelines) in order to amass a solid base of evidence for informing decommissioning policy. Research across a broad geographical range is also required to assess variability between different locations under differing environmental regimes.

\section{ETHICS STATEMENT}

This study was carried out in accordance with the recommendations of "Animal Welfare Act (2002)" and the requirements of the Australian Code of Practice for the Care and Use of Animals for Scientific Purposes (7th Edition 2004) 'The Code' and the UWA Animal Ethics Committee. The protocol was approved by the UWA Animal Ethics Committee.

\section{REFERENCES}

Althaus, F., Hill, N., Ferrari, R., Edwards, L., Przeslawski, R., Schönberg, C. H. L., et al. (2015). A standardised vocabulary for identifying benthic biota and substrata from underwater imagery: the CATAMI classification scheme. PLoS One 10:e0141039. doi: 10.1371/journal.pone.0141039

Anderson, M. J. (2017). "Permutational Multivariate Analysis of Variance (PERMANOVA)," in Wiley StatsRef: Statistics Reference Online, eds N. Balakrishnan, T. Colton, B. Everitt, W. Piegorsch, F. Ruggeri, and J. L. Teugels (Hoboken, NJ: John Wiley \& Sons).

Bahmanpour, M. H., Pattiaratchi, C., Wijeratne, E. M. S., Steinberg, C., and D'Adamo, N. (2016). Multi-year observation of Holloway current along the shelf edge of north Western Australia. J. Coastal Res. 75, 517-521. doi: 10.2112/ SI75-104.1

Beeden, R., Maynard, J., Puotinen, M., Marshall, P., Dryden, J., Goldberg, J., et al. (2015). Impacts and recovery from severe tropical cyclone Yasi on

\section{DATA AVAILABILITY STATEMENT}

All datasets generated for this study are included in the manuscript.

\section{AUTHOR CONTRIBUTIONS}

DB conceived the idea and secured access to the footage. PT, AF, and $\mathrm{DB}$ designed the study. PT, AF, AD, and CP completed the analysis. PT compiled the data and wrote the manuscript with contributions from all other authors.

\section{ACKNOWLEDGMENTS}

We would like to acknowledge Woodside Energy Ltd. (the operator of the platform) and we greatly appreciate the efforts of Mr. John Watt in facilitating access to Woodside Energy Ltd. video archives. Thanks also to subsea engineers, Mr. Mike Biczo and Mr. Derek Mackay, and ROV supervisor Mr. James Eu for their efforts in accessing the video and explaining technical aspects of platform structure, platform cleaning, and data collection and storage. Thanks also to Dr. Luke Smith and Ms. Kate Swain, environment staff at Woodside Energy Ltd., for reviewing the manuscript. This study was initiated as part of the SEA-SERPENT (South-East Asia Scientific and Environmental ROV Partnership using Existing Industrial Technology) project.

\section{SUPPLEMENTARY MATERIAL}

The Supplementary Material for this article can be found online at: https://www.frontiersin.org/articles/10.3389/fmars. 2018.00471/full\#supplementary-material

TABLE S1 | Transect lengths and replicate numbers (in parentheses) according to year and depth for surveys of invertebrates and fishes associated with GWA platform. Replicates for invertebrates refer to quadrats examined along the length of a transect, while replicates for fishes refer to the number of transects completed. Frames examined from 125 m during 2008 were obtained from stationary footage obtained 3 months prior to footage for other depths. Note the different depth strata examined for fishes between 2006 and 2008.

the great barrier reef. PLoS One 10:e0121272. doi: 10.1371/journal.pone.012 1272

Bell, N., and Smith, J. (1999). Coral growing on North Sea oil rigs. Nature 402, 601-601. doi: 10.1038/45127

Bole, J. B., Ebbesmeyer, C. C., and Romea, R. D. (1994). Soliton Currents in the South China Sea: Measurement and Theoretical Modeling. Houston, TX: Offshore Technology Conference.

Brokovich, E., Einbinder, S., Shashar, N., Kiflawi, M., and Kark, S. (2008). Descending to the twilight-zone: changes in coral reef fish assemblages along a depth gradient down to 65 m. Mar. Ecol. Prog. Ser. 371, 253-262. doi: 10.3354/ meps07591

Brown, K. E., Cox, E., Jokiel, P. L., Ku'ulei Rodgers, E., Smith, W. R., Tissot, B. N., et al. (2004). Development of benthic sampling methods for the coral reef assessment and monitoring program (CRAMP) in Hawai'i. Pac. Sci. 58, 145-158. doi: 10.1353/psc.2004. 0013 
Caselle, J. E., Love, M. S., Fusaro, C., and Schroeder, D. (2002). Trash or habitat? Fish assemblages on offshore oilfield seafloor debris in the Santa Barbara Channel, California. ICES J. Mar. Sci. 59, S258-S265. doi: 10.1006/jmsc. 2002. 1264

Claisse, J. T., Pondella, D. J. II, Love, M., Zahn, L. A., Williams, C. M., and Bull, A. S. (2015). Impacts from partial removal of decommissioned oil and gas platforms on fish biomass and production on the remaining platform structure and surrounding shell mounds. PLoS One 10:e0135812. doi: 10.1371/journal. pone. 0135812

Claisse, J. T., Pondella, D. J., Love, M., Zahn, L. A., Williams, C. M., Williams, J. P., et al. (2014). Oil platforms off California are among the most productive marine fish habitats globally. Proc. Natl. Acad. Sci. U.S.A. 111, 15462-15467. doi: 10.1073/pnas.1411477111

Clarke, K. R. (1993). Non-parametric multivariate analyses of changes in community structure. Aust. J. Ecol. 18, 117-143. doi: 10.1111/j.1442-9993.1993. tb00438.x

Clarke, K. R., and Gorley, R. (2006). PRIMER v6: User Manual/Tutorial. Plymouth: PRIMER-E.

Clark, S., and Edwards, A. J. (1999). An evaluation of artificial reef structures as tools for marine habitat rehabilitation in the Maldives. Aquat. Conserv. 9, 5-21. doi: 10.1002/(SICI)1099-0755(199901/02)9:1<5::AID-AQC330>3.0.CO;2-U

Colton, D. E., and Alevizon, W. S. (1981). Diurnal variability in a fish assemblage of a Bahamian coral reef. Environ. Biol. Fishes 6, 341-345. doi: 10.1007/ BF00005762

Creed, J. C., de Junqueira, A. O. R., Fleury, B. G., Mantelatto, M. C., and OigmanPszczol, S. S. (2017). The Sun-Coral Project: the first social-environmental initiative to manage the biological invasion of Tubastraea spp. in Brazil. Manag. Biol. Invasions 8, 181-195. doi: 10.3391/mbi.2017.8.2.06

Dokken, Q., Withers, K., and Childs, S. T. R. (2000). Characterization and Comparison of Platform Reef Communities off the Texas Coast. Corpus Christi, TX: Center for Coastal Studies.

Engås, A., Løkkeborg, S., Ona, E., and Soldal, A. V. (1996). Effects of seismic shooting on local abundance and catch rates of cod ((Gadus morhua) and haddock )(Melanogrammus aeglefinus). Can. J. Fish. Aquat. Sci. 53, 2238-2249. doi: $10.1139 /$ f96- 177

Fang, H., and Duan, M. (2014). Offshore Operation Facilities, Equipment and Procedures. Houston, TX: Gulf Professional Publishing.

Fletcher, W., and Santoro, K. (2012). "Status reports of the fisheries and aquatic resources of Western Australia 2011/12: the state of the fisheries," in Department of Fisheries, eds W. Fletcher and K. Santoro (Perth: Western Australia).

Forteath, G. N. R., Picken, G. B., Ralph, R., and Williams, J. (1982). Marine growth studies on the North Sea oil and gas platform Montrose Alpha. Mar. Ecol. Prog. Ser. 8, 61-68. doi: 10.3354/meps008061

Fowler, A. M., and Booth, D. J. (2012). Evidence of sustained populations of a small reef fish on artificial structures. Does depth affect production on artificial reefs? J. Fish Biol. 80, 613-629. doi: 10.1111/j.1095-8649.2011.03201.x

Fowler, A. M., Macreadie, P. I., Jones, D. O. B., and Booth, D. J. (2014). A multi-criteria decision approach to decommissioning of offshore oil and gas infrastructure. Ocean Coast. Manag. 87, 20-29. doi: 10.1016/j.ocecoaman.2013. 10.019

Friedlander, A. M., Ballesteros, E., Fay, M., and Sala, E. (2014). Marine communities on oil platforms in gabon, west Africa: high biodiversity oases in a low biodiversity environment. PLoS One 9:e103709. doi: 10.1371/journal.pone. 0103709

Gallaway, B. J., Szedlmayer, S. T., and Gazey, W. J. (2009). A life history review for red snapper in the gulf of Mexico with an evaluation of the importance of offshore petroleum platforms and other artificial reefs. Rev. Fish. Sci. 17, 48-67. doi: 10.1080/10641260802160717

Gass, S. E., and Roberts, J. M (2006). The occurrence of the cold-water coral Lophelia pertusa (Scleractinia) on oil and gas platforms in the North Sea: colony growth, recruitment and environmental controls on distribution. Mar. Pollut. Bull. 52, 549-559. doi: 10.1016/j.marpolbul.2005. 10.002

George, R. Y., and Thomas, P. J. (1979). Biofouling community dynamics in Louisiana shelf oil platforms in the gulf of Mexico. Rice Inst. Pam. 65, 553-574.

Hobson, E. (1965). Diurnal-nocturnal activity of some inshore fishes in the Gulf of California. Copiea 1965, 291-302. doi: 10.2307/1440790
Holloway, P. E. (2001). A regional model of the semidiurnal internal tide on the Australian North West Shelf. J. Geophys. Res. Oceans 106, 19625-19638. doi: 10.1029/2000JC000675

Hwang, J.-S., Dahms, H.-U., Huang, K. L., Huang, M.-Y., Liu, X.-J., Khim, J. S., et al. (2018). Bioaccumulation of trace metals in octocorals depends on age and tissue compartmentalization. PLoS One 13:e0196222. doi: 10.1371/journal. pone.0196222

Jørgensen, D. (2012). OSPAR's exclusion of rigs-to-reefs in the North Sea. Ocean Coast. Manag. 58, 57-61. doi: 10.1016/j.ocecoaman.2011.12.012

Kaiser, M. J. (2006). The Louisiana artificial reef program. Mar. Policy 30, 605-623. doi: 10.1371/journal.pone.0203873

Karlson, R., and Cornell, H. (1998). Scale-dependent variation in local vs. regional effects on coral species richness. Ecol. Monogr. 68, 259-274. doi: 10.1890/00129615(1998)068[0259:SDVILV]2.0.CO;2

Kohler, K. E., and Gill, S. M. (2006). Coral Point Count with Excel extensions (CPCe): a Visual Basic program for the determination of coral and substrate coverage using random point count methodology. Comput. Geosci. 32, 1259-1269. doi: 10.1016/j.cageo.2005.11.009

Kolian, S. R., Sammarco, P. W., and Porter, S. A. (2017). Abundance of corals on offshore oil and gas platforms in the gulf of Mexico. Environ. Manag. 60, 357-366. doi: 10.1007/s00267-017-0862-z

Laidig, T. E., Krigsman, L. M., and Yoklavich, M. M. (2012). Reactions of fishes to two underwater survey tools, a manned submersible and a remotely operated vehicle. Fish. Bull. 112, 54-67.

Love, M. S., Caselle, J., and Snook, L. (1999). Fish assemblages on mussel mounds surrounding seven oil platforms in the Santa Barbara Channel and Santa Maria Basin. Bull. Mar. Sci. 65, 497-513.

Love, M. S., Caselle, J. E., and Snook, L. (2000). Fish assemblages around seven oil platforms in the Santa Barbara Channel area. Fish. Bull. 98, 96-117.

Lyne, V., Fuller, M., Pla, B., Martin, M., and Scoot, R. (2006). "Ecosystem characteristics of Australia's North West shelf," in North West Shelf Joint Environmental Management Study, Book 4, ed. CSIRO (Perth: CSIRO).

Macreadie, P. I., Fowler, A. M., and Booth, D. J. (2011). Rigs-to-reefs: will the deep sea benefit from artificial habitat? Front. Ecol. Environ. 9, 455-461. doi: 10.1890/100112

Macreadie, P. I., McLean, D. L., Thomson, P. G., Partridge, J. C., Jones, D. O. B., Gates, A. R., et al. (2018). Eyes in the sea: unlocking the mysteries of the ocean using industrial, remotely operated vehicles (ROVs). Sci. Total Environ. 634, 1077-1091. doi: 10.1016/j.scitotenv.2018.04.049

Martin, C., and Lowe, C. (2010). Assemblage structure of fish at offshore petroleum platforms on the San Pedro Shelf of Southern California. Mar. Coast. Fish. 2, 180-194. doi: 10.1577/C09-037.1

McLean, D. L., Macreadie, P., White, D. J., Thomson, P. G., Fowler, A., Gates, A. R., et al. (2018a). "Understanding the global scientific value of industry ROV data, to quantify marine ecology and guide offshore decommissioning strategies," in Proceedings of the Offshore Technology Conference Asia, (Kuala Lumpur: Offshore Technology Conference). doi: 10.4043/28312-MS

McLean, D. L., Taylor, M. D., Partridge, J. C., Gibbons, B., Langlois, T. J., Malseed, B. E., et al. (2018b). Fish and habitats on wellhead infrastructure on the north west shelf of Western Australia. Cont. Shelf Res. 164, 10-27. doi: 10.1016/j.csr. 2018.05.007

McLean, D. L., Partridge, J. C., Bond, T., Birt, M. J., Bornt, K. R., and Langlois, T. J. (2017). Using industry ROV videos to assess fish associations with subsea pipelines. Cont. Shelf Res. 141, 76-97. doi: 10.1016/j.csr.2017.05.006

McLoughlin, R. J., and Young, P. C. (1985). Sedimentary provinces of the fishing grounds of the north west shelf of Australia: grain size frequency analysis of surficial sediments. Aust. J. Mar. Freshw. Res. 36, 671-681. doi: 10.1071/ MF9850671

Nagelkerken, I., Dorenbosch, M., and Verberk, W. C. E. P. (2000). Day-night shifts of fishes between shallow-water biotopes of a Caribbean bay, with emphasis on the nocturnal feeding of Haemulidae and Lutjanidae. Mar. Ecol. Prog. Ser. 194, 55-64. doi: 10.3354/meps194055

Normandeau Associates Inc. (2012). Effects of Noise on Fish, Fisheries, and Invertebrates in the U.S. Atlantic and Arctic from Energy Industry SoundGenerating Activities. Bedford: Normandeau Associates, Inc.

Nott, J., and Hayne, M. (2001). High frequency of 'super-cyclones' along the Great Barrier Reef over the past 5,000 years. Nature 413, 508-512. doi: 10.1038/ 35097055 
Parente, V., Ferreira, D., Moutinho dos Santos, E., and Luczynski, A. (2006). Offshore decommissioning issues: deductibility and transferability. Energy Policy 34, 1992-2001. doi: 10.1016/j.enpol.2005.02.008

Perkol-Finkel, S., Shashar, N., and Benayahu, Y. (2006). Can artificial reefs mimic natural reef communities? The roles of structural features and age. Mar. Environ. Res. 61, 121-135. doi: 10.1016/j.marenvres.2005.08.001

Pradella, N., Fowler, A. M., Booth, D. J., and Macreadie, P. I. (2014). Fish assemblages associated with oil industry structures on the continental shelf of north-western Australia. J. Fish Biol. 84, 247-255. doi: 10.1111/jfb.12274

Rayson, M. D., Ivey, G. N., Jones, N. L., Lowe, R. J., Wake, G. W., and McConochie, J. D. (2015). Near-inertial ocean response to tropical cyclone forcing on the Australian North-West Shelf. J. Geophys. Res. Oceans 120, 7722-7751. doi: 10.1002/2015JC010868

Reeds, K. A., Smith, J. A., Suthers, I. M., and Johnston, E. L. (2018). An ecological halo surrounding a large offshore artificial reef: sediments, infauna, and fish foraging. Mar. Environ. Res. doi: 10.1016/j.marenvres.2018.07.011 [Epub ahead of print].

Rooker, J. R., Dokken, Q. R., Pattengill, C. V., and Holt, G. J. (1997). Fish assemblages on artificial and natural reefs in the Flower Garden Banks National Marine Sanctuary, USA. Coral Reefs 16, 83-92. doi: 10.1007/s003380050062

Sammarco, P. W., Porter, S. A., Genazzio, M., and Sinclair, J. (2015). Success in competition for space in two invasive coral species in the western Atlantic Tubastraea micranthus and T. coccinea. PLoS One 10:e0144581. doi: 10.1371/ journal.pone.0144581

Schroeder, D. M., and Love, M. S. (2004). Ecological and political issues surrounding decommissioning of offshore oil facilities in the Southern California Bight. Ocean Coast. Manag. 47, 21-48. doi: 10.1016/j.ocecoaman. 2004.03.002
Stanley, D. R., and Wilson, C. A. (1997). Seasonal and spatial variation in the abundance and size distribution of fishes associated with a petroleum platform in the northern Gulf of Mexico. Can. J. Fish. Aquat. Sci. 54, 1166-1176.

Surespek Iss PTY Ltd (2009). GWA Bulk Marine Growth Removal Site Report. Perth: Surespek Iss PTY Ltd.

van der Stap, T., Coolen, J. W. P., and Lindeboom, H. J. (2016). Marine fouling assemblages on offshore gas platforms in the southern north sea: effects of depth and distance from shore on biodiversity. PLoS One 11:e0146324. doi: 10.1371/journal.pone.0146324

Weil, E., Rogers, C. S., and Croquer, A. (2015). "Octocoral diseases in a changing ocean," in Marine Animal Forests: The Ecology of Benthic Biodiversity Hotspots, eds S. Rossi, L. Bramanti, A. Gori, and C. Orejas Saco del Valle (Cham: Springer International Publishing).

Woodside, A. (2008). 2008 Goodwyn A Marine Growth Survey by ROV-Final Report. Perth: Woodside Energy LTD.

Conflict of Interest Statement: The authors declare that the research was conducted in the absence of any commercial or financial relationships that could be construed as a potential conflict of interest.

Copyright (c) 2018 Thomson, Fowler, Davis, Pattiaratchi and Booth. This is an openaccess article distributed under the terms of the Creative Commons Attribution License (CC BY). The use, distribution or reproduction in other forums is permitted, provided the original author(s) and the copyright owner(s) are credited and that the original publication in this journal is cited, in accordance with accepted academic practice. No use, distribution or reproduction is permitted which does not comply with these terms. 